\title{
The Basic Principles of Creation of Habitable Planets around Stars in the Milky Way Galaxy
}

\author{
Alexander N. Safronov \\ Obukhov Institute of Atmospheric Physics, Russian Academy of Sciences/Pyzhevskii per. 3, Moscow, Russia \\ Email: safronov_2003@mail.ru
}

How to cite this paper: Safronov, A.N. (2016) The Basic Principles of Creation of Habitable Planets around Stars in the Milky Way Galaxy. International Journal of Astronomy and Astrophysics, 6, 512-554. http://dx.doi.org/10.4236/ijaa.2016.64039

Received: October 31, 2016

Accepted: December 26, 2016

Published: December 29, 2016

Copyright $\odot 2016$ by author and Scientific Research Publishing Inc. This work is licensed under the Creative Commons Attribution International License (CC BY 4.0).

http://creativecommons.org/licenses/by/4.0/ (c) (i) Open Access

\begin{abstract}
The principle of habitable planets creation of near stars in our galaxy was developed. It was shown that the Earth and the Moon formed as a result of thermal nuclear explosion (TNE) after a collision with a small comet. The comet has broken through the proto-Earth crust, and created conditions for liquid-drop division into the Earth and the Moon. It is shown that the comet impact on the proto-Earth led to formation of continents as well as to formation of the Moon, seas, oceans and atmosphere and to creation of conditions for life origin. The analysis of kimberlitic pipes distribution, as markers of comet fragments motion under a crust, shows that the comet has broken up under crust with formation of many gas bubbles. An analysis of the Martian topography revealed that the comet hit Mars not under a glancing angle. As a result, the products of TNE remained under the Marian crust. The track of the comet movement under the Venus crust was also established. It is shown that the planet surface near comet track is spotted by numerous cracks.
\end{abstract}

\section{Keywords}

Habitability, Comet Impact, Liquid Water, Origin of Life, Pangaea, Earth-Like Exoplanets Topography, Diamond Structures, Astrobiology

\section{Introduction}

There are the various explanations of the formation of the Moon, Earth's natural satellite. These explanations could be grouped as following hypotheses: a hypothesis of centrifugal division, a capture hypothesis, a hypothesis of joint formation from a protoplanetary dust disk, an evaporation hypothesis, a hypothesis of many moon, a collision hypothesis (see details in [1]-[6]). Recently a hypothesis of the nuclear explosion [7] [8] has been suggested.

These studies were performed by three groups of the scientists who used fundamen- 
tally different approaches to the problem of the Moon origin, namely astronomers and astrophysics, geochemists and more recently nuclear physicists. In process of availability of information about Moon, one or other hypothesis was dominated.

So the Darwin's hypothesis of centrifugal separation of the Moon from the Earth which has been put forward [9] was originally prevailed. In Darwin's model, the Moon was formed from resonant effects of solar tides and centrifugal forces at fast rotation of the Earth around its axis. However, the study [10] showed that solar tide could not lead to the Darwin's fission. Subsequently, [11] [12] and [13] updated Darwin's hypothesis by including models for the thermal evolution and internal differentiation history of the Earth. The main problem in the Darwin-Ringwood-Wise model was in the fact that the Earth-Moon formation precedes at a very high angular momentum of the protoEarth. The occurrence of such a large angular momentum at proto-Earth is impossible to explain, as well as it is difficult to explain his sudden disappearance at the modern Earth time.

In 70th years of the last century, the great impact hypothesis (GIH) [14] [15] was dominated. According to this hypothesis, at a final stage of its formation, the protoEarth was in collision with a large planet which size is approx. equal to size of the Mars. The space body, which impacted into proto-Earth, was called Thea. As a result of the collision a large amount of molten mantle has been thrown out into a near-Earth orbit with subsequent formation of the Moon. Computer simulations showed that such a scenario is indeed possible (see for example [2]).

However later we learned that the measurements of oxygen [16] [17], chromium [18] [19], titanium [20] [21], potassium [22], and silicon [23] [24] [25] [26] isotopic compositions of lunar rocks indicated that the Moon and the bulk silicate Earth show a very high degree of similarity. In addition, the details of the discussion about discrepancy between dynamical models and geochemical observations could be found in [8] and [27]. Actually, it was not possible to find any geochemical markers specifying the presence of a massive body such as Thea, so GIH was disproved.

In [8], it was offered that a nuclear explosion occurred at the core-mantle boundary inside of proto-Earth, due to impact with $100 \mathrm{~km}$ space object. However, the simulation, suggested in [7] [8], should lead to strong pollution of the Earth's and the Moon's surface by the isotopes of the planet's core.

At the same time, the absence of Fe on the Moon's surface makes a contrast to Mars's surface. Thus, at the moment, when a nuclear explosion in the proto-Earth mantle-core occurred, the Moon has already separated from the proto-Earth. From the [8], it was not clear, why after the explosion of a core-mantle boundary, the core of proto-Earth did not detonate. The considerable amount of ${ }^{3} \mathrm{He}$ on the Moon surface does not support of the hypothesis [8] also.

From the presence of ${ }^{3} \mathrm{He}$ and $\mathrm{H}_{2} \mathrm{O}$, it is possible to draw a conclusion on a thermal warming of a planet core (thermal nuclear explosion, TNE), but not about a powerful nuclear explosion. In the middle of the visible surface of the Moon, there is a trace of the umbilical cord, so most likely that the separation occurred in the liquid phase due to a superfluous pressure. Better to say, that due to local pressure excess in the magma, 
the proto-Earth was transformed into an elongated ellipsoid, which later was transformed into hydrodynamic eight with the subsequent division of two halves. In an outer space were only the fragments of proto-Earth crust. They were cut of near crash site of a celestial body. Such interpretation of collision would lead to the following assumptions: first, the fallen body was a comet, instead of an asteroid; secondly, the fallen body had a small size. In addition, we will note that the average size of comets is much smaller than $100 \mathrm{~km}$-diameter asteroid, declared in [7] [8].

It is necessary to notice that an idea of formation of the Earth due to collision with a comet is not new, well before William Whiston mentioned this possibility [28]. However, the coincidence of this study with Whiston theory is purely formal, and it is based on the fact of comet collision with Earth. In this manuscript, we show that a comet is just a delay-action detonator, which has induced thermal nuclear explosive processes inside of the planet.

The ultimate goal of this study is the development of principles for creation of new habitable planets around other stars.

\section{Materials and Methods}

\subsection{Earth Data}

In this study for gluing the continent pieces that were destroyed by the effects of impact processes in the Earth's crust, GIS-system tools such as ArcGlobe, ArcInfo were applied [29]. The open-source software tool GPlates, which available online [30] was applied for visualization and analysis of the continent moving and for comparison between different methods of continent gluing into one supercontinent. The work manual for GPlates can be found in [31] [32] [33] [34].

\subsection{Diamond Structures}

The database of diamond deposits (DIADATA), which developed at the International Peace Research Institute, Oslo (PRIO) and at the Norwegian University of Science and Technology (NTNU), was used [35] [36]. The DIADATA is a comprehensive list of diamond occurrences throughout the world accompanied by geographic coordinates, the geological form of the diamond, and the discovery and production dates. The data are available on-line at the Diamond-Resources website [37].

\subsection{Lunar Data}

\subsubsection{Lunar Topographic Data}

In this study as the lunar topographic data were used smoothed data ULCN-2005 and Kaguya. A Unified Lunar Control Network (ULCN-2005) and lunar topographic model based on a combination of Clementine images and a previous study (ULCN and CLCN) derived from the Earth-based, Apollo photographs, Mariner 10, Galileo images [38]. The ULCN-2005 datasets connects the four different types of image data and its accuracy is relatively well quantified. The pre-ULCN Lunar study was described in [39]. The CLCN Lunar study was derived from Clementine images and measurements on 
Clementine 750-nm images. The mosaic map was used to produce the Clementine UVVIS digital image model [40] and the Near-Infrared Global Multispectral Map of the Moon from Clementine [41]. About using Clementine Mosaics in ULCN-2005 (see also [42]).

In more details the product ULCN-2005:lpo_ht, which based on polynomial interpolating a grid of Lunar radius value (ULCN-2005:radii) was used in this study. The GIS dataset of the Moon data could be found in [43] and datasets [44]. As well the Kaguya Lunar Global Topography (from Kaguya laser altimeter, LALT), as also known as SELENE (SELenological and ENgineering Explorer) instrument was used for comparison. The details of Kaguya satellite (Japan), 2007-2009 and Kaguya Lunar Global Topography could be found in [45].

\subsubsection{Lunar Prospector of Fe and Th Data}

In this study as indicators of lunar surface melting were used the data obtained from the satellite Lunar Prospector (LP), Satellite LP (USA), 1998-1999 (see [46]).

This dataset was named as LP Reduced Spectrometer Data (Special Products) [47]. These products included the $0.5^{\circ} \times 0.5^{\circ}$ abundance data products for iron (Fe) and thorium (Th), which were prepared by a gamma ray spectrometer [48]. The absolute abundances data for thorium are presented in units of ppm and the absolute abundances data for iron are given in units of $\mathrm{FeO}$ weight percent. A description of these products could be found in [49] [50] [51].

\subsubsection{Free-Air Gravity Accelerations of the Moon}

In this study, the $0.25^{\circ} \times 0.25^{\circ}$ resolution of free-air gravity accelerations of the Moon was used. This Clementine Gravity Map was obtained during the Clementine satellite mission, (USA), 1994. As reported in [52] [53], the global topographic and gravitational field models derived from data collected by the Clementine spacecraft gave a new picture of the shape and internal structure of the Moon. The gravity anomalies are derived from GLGM-2 spherical harmonic gravity model. A spherical harmonic model of the lunar gravity field complete to degree and order 70 has been developed from $\mathrm{S}$ band Doppler tracking data from the Clementine mission, as well as historical tracking data from Lunar Orbiters 1 - 5 and the Apollo 15 and 16 subsatellites (For more details, see [54]). The observation is free-air gravity in milligals.

\subsection{Martian Topography}

Martian topography, called as the Mars Global GIS, was obtained from the site [55]. Infrared Mars Orbiter Laser Altimeter (MOLA-2) obtained this topography, 1997-2001, from the board of the Mars Global Surveyor (MGS) satellite. Information about the MOLA instrument and data products can be found in [56] [57] [58]. The instrument profiled surface features at a maximum vertical resolution of $\sim 30 \mathrm{~cm}$ and along-track spatial resolution of 300 to $400 \mathrm{~m}$. Using MOLA data the MOLA Science Team has produced a very high resolution topographic shaded relief map with resolution $0.125^{\circ}$ (300 dots per inch). 


\subsection{Venusian Topography}

The Venusian Topography Map available on line at [59]. The Venusian topography was made by using synthetic aperture radar (SAR) during Magellan satellite mission (see [60] [61]). The details about Venusian topography may be found in [62] [63] [64].

\section{The Moon and the Earth Process Formation}

In this manuscript, we show that a comet is a delay-action detonator, which has induced thermal nuclear explosive processes inside of the planet.

Let's begin with dating of the Earth and the Moon formation. The dating result strongly depends on the impact hypothesis. If the Earth and the Moon crust are the parts of the proto-Earth crust, they certainly have the same composition, and the process of crust drilling will not be able to help us to learn anything about impact dating. So all estimations such as $4.57 \mathrm{Ga}$ for the Earth and $4.4 \mathrm{Ga}$ for the Moon look useless.

Therefore, the question about the dating of a comet impact and about the Earth and the Moon formation time is extremely difficult. Dating is possible only on base of associated factors.

\subsection{The Dating of the Moon Formation}

Let's generalize this reasoning about the Moon as a more simple case. If we assume that the Moon rotates around the Earth for billions of years and since the Moon does not have a dense atmosphere, the meter layer of space dust could accumulate on its surface. However, a thick layer of dust on the Moon surface was not recorded. Proceeding from the fact that the lunar dust layer thickness is equal to $\sim 0.1-0.15 \mathrm{~m}$, we can estimate the age of the Moon. According to osmium (Os) and iridium (Ir) sedimentations on the bottom of Pacific Ocean [65] the speed of sedimentation of a space dust has been estimated. It was shown that the values are in the range of $0.6-1.0 \times 10^{8} \mathrm{~kg} /$ year. In the later works [66] [67], the range of values varied in $1.5-1.7 \times 10^{8} \mathrm{~kg} /$ year.

Then the lunar dust could be formed within the following time:

$$
T=(\rho h S) / \varsigma
$$

where

$$
h=0.10-0.15 \mathrm{~m}, S=510 \times 10^{12} \mathrm{~m}^{2}, \varsigma=1 \times 10^{8} \mathrm{~kg} / \text { year. }
$$

Taking into account that the lunar dust density is approximately equal to the density of the upper layers of the lunar regolith, which has $\rho \sim 1000 \mathrm{~kg} / \mathrm{m}^{3}$, we can calculate that the time of Moon formation is equal to $T=510-765 \mathrm{Ma}$. We encourage the reader to understand that the age of the Earth and the Moon approximately corresponds to an age of the supercontinent Pangea formation (650 Ma), when the most of the planet's crust was spited and re-melted.

\subsection{The Dating of the Earth Formation}

As known, the Pangaean supercontinent proposed by Alfred Wegener is a huge rounded 
to oval landmass [68]. The fit of the Gondwana continents, prior to the breakup of Pangaea was investigated in [69]. Reconstruction of Pangaea by [70] was performed as well. Recently, a lot of work dedicated to the continents separation and movement. The modern global plate motion models provide a set of continuously closing topological plate polygons with associated plate boundaries and plate velocities since the break-up of the supercontinent Pangea.

There are a number of approaches to study of the continents motion. The first oldest model of them is a traditional plate tectonic model, which based on the interpretation of the seafloor spreading record and on paleomagnetic data to reconstruct the ocean basins and continents, [71]-[76]. The other kind model for prediction of plate motions is the coupled geodynamic-plate model, which used model plate boundary locations and mantle density heterogeneity [77] [78] [79] [80]. The satellite-derived gravity anomalies and an updated set of magnetic anomaly identifications was proposed in [81] to use to construct seafloor spreading isochrones for all the major oceanic plates and to predict the plate motion. The new global marine gravity model based on new radar altimeter measurements from satellites CryoSat-2 and Jason-1 were described in [82] (see also Group publications on web page [83]).

However, we are not interested in the process of continental drift itself, but we concentrate attention on factors that led to the formation of the supercontinent Pangea.

As is known, Pangaea was formed from pieces of supercontinent Pannotia [84] [85] [86], which existed in a time range of 600 - 540 Ma. After a thermal nuclear explosion (TNE) the kernel of a planet had come to sharp cooling, so the dating can be slightly refined and placed in the previous Cryogenian period of time, 720 - $635 \mathrm{Ma}$. At this period, the Earth looked like the Snowball Earth [87]. Thus, pieces of Pangaea were inherited after the collapse of Rodinia, which was broken up 750 - $600 \mathrm{Ma}$.

Both dates of formation the Moon and the Earth are concurring, so we are talking about period around $\sim 700-600 \mathrm{Ma}$.

\subsection{The Process of Pangaea Formation}

We will make a speculative experiment, which aims to dispel the illusions about correctness of the modern models of collisions.

Let us throw down from the top of the Tower of Pisa the various bodies with the linear size of the D, and explore the crater formed from the collisions. The first we will throw a stone ball. It is obvious that the crater size will be determined by the gravitational interaction, and it is possible to consider that in the case of the stone ball fall from a height into the soft soil, the crater diameter as a first approximation will be equal to $\sim \mathrm{D}$.

Next, we will throw down a cannonball contained contact detonator. Taking into account a quantity of a cannon power, which can take place in such sphere; it is possible to roughly estimate the size of a crater as $\sim 10 \mathrm{D}$.

The third, from the Tower of Pisa we drop down the same diameter ball, but now filled with a nuclear charge. In this case, the crater size would be at least 10 times more, 
than one from a cannon ball, i.e. it will equal to $\sim 100 \mathrm{D}$. The next craters size proportion, which is depending from the explosion type, could be presented as 1:10:100.

Someone can say that the Leaning Tower of Pisa experiment is primitive and elementary. However, we will bring back the same question in the following way. What should be the diameter of the space body, if on the Earth's surface the crater with diameter of $1000-1500 \mathrm{~km}$ was formed? Why the nuclear reactions energy in a collision with a planetary body having an active core was not taken into account?

Finally, from a hypothetical experiment with the Leaning Tower of Pisa, it is possible to draw a conclusion that a crater on the Earth surface with the diameter of $1000-1500$ $\mathrm{km}$ could be formed in result of a collision with a small celestial body having a size that is equal to $\sim 10-15 \mathrm{~km}$. And this result is already fundamentally different from what was published by other researchers earlier.

Let's note, that according JPL's Solar System Dynamics Group small-body database (SBDB, http://ssd.jpl.nasa.gov/sbdb_query.cgi) the next comets have diameter more than $10 \mathrm{~km}$ : 1P/Halley (11.0 km), 10P/Tempel $2(10.6 \mathrm{~km}), 28 \mathrm{P} /$ Neujmin $1(21.4 \mathrm{~km}), 109 \mathrm{P} /$ Swift-Tuttle (26 km), 29P/Schwassmann-Wachmann 1 (30.8 km), 65P/Gunn (10.8 km), 99P/Kowal $1(10.2 \mathrm{~km})$ and 167P/CINEOS $(66.17 \mathrm{~km})$.

Below we will consider the features of the Pangaea (Rodinia) structure process formation as a result of comet impact. Let's note that this study does not provide an evidence to suggest that in the process of decay the pieces of supercontinents were dispersed over the long distances. Actually, we investigate a structure of hypothetical continent Rodinia.

Assuming the primary proto-Earth planet was formed in result of uniformly and gradually cooling proto planetary dust disk, the density of planet crust should be an isotropic and homogeneous at the surface. Then the shock processes after the fall of the comet will be distributed in concentric circles from the point of impact of a comet, the same way as ripples spread from the thrown stone. Thus, continents, as crust pieces of the proto-Earth, at pasting should be within the circles that could be drawn around the point of impact of a celestial body. This principle we applied as a base for continents gluing. The general scheme of comet impact in the protoEarth was shown in Figure 1.

In this study, for gluing the proto-Earth crust pieces was used ArcGlobe; the visualization of the results was carried out with help of the GIS ArcInfo. The gluing in southern hemisphere is shown in Figure 2. The comet crater is located in the south of Africa and its radius is equal to $\sim 1500 \mathrm{~km}$. In Figure 2, the arrows indicate those parts of the continents where shock loads have led to the formation of the edges of continents. For example, chips on the west coast of South America correspond to faults between Antarctica and Australia (see a circle with a radius of $4500 \mathrm{~km}$ ). Radial break lines between Africa and the South America, as well as between Antarctica and Africa are directed to epicenter of a comet impact.

Thus, it has to be concluded that the continents split directly in the moment of a comet impact. However as it is known continents of the southern hemisphere did not separated, and it could be concluded that viscosity of magma was high, and the planet's 


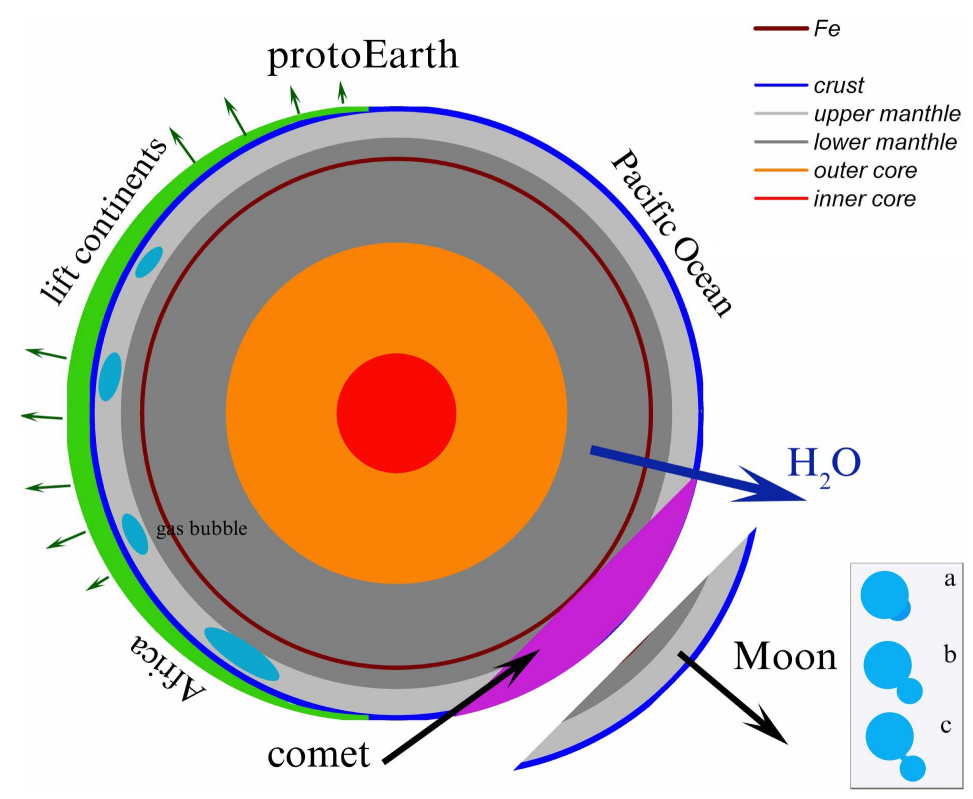

Figure 1. The comet impact, the $\mathrm{CO}_{2}$ gas bubbles formation under a planet crust, the thermal expansion of the gas bubbles, the subsequent thermal nucleus explosion, the lifting continents and a Moon formation are shown in the general scheme. In the figure plate the drop hydrodynamic the Earth and the Moon separation process from the viscous magma of the proto-Earth is schematically displayed.

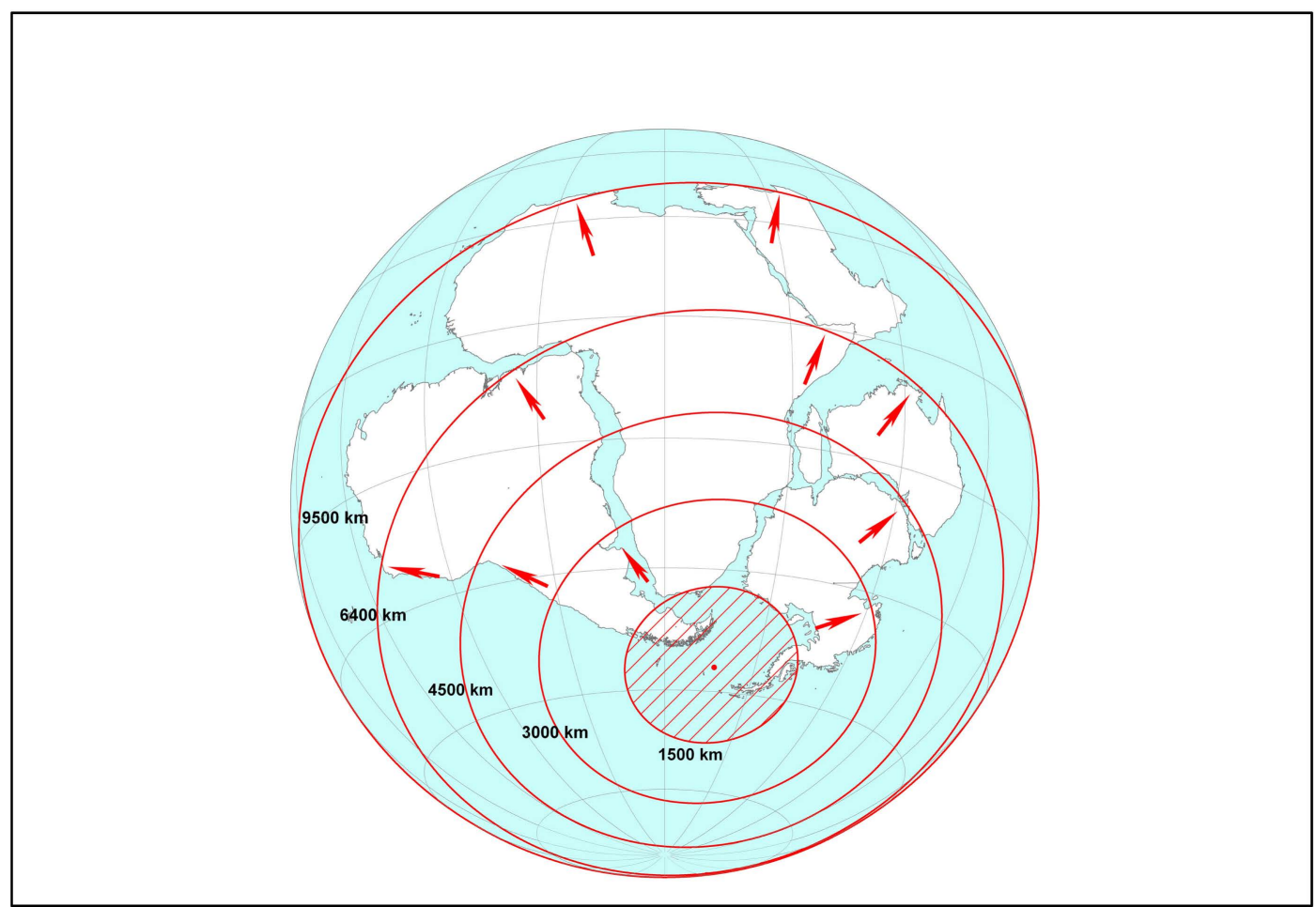

Figure 2. The result of the gluing process of Africa, South America, Antarctica and Australia continents is shown. In addition, the circles represented the shock waves around the crash site of a comet. Arrows displayed the key parts of the Pangea supercontinent splitting. The direction of the comet impact in the offshore water of the southern Pacific Ocean is shown also. 
core was not overheated. Also, note that a large part of the Earth crust near to explosion epicenter is absent, i.e. comet blow was moving toward the planet's surface and it is a reason why the part of the proto-Earth crust is absent. The comet impact directed to south water area of the Pacific Ocean. In result of the analysis of Figure 2, we can conclude that the crust of the proto-Earth has to be rigid, magma has to be viscous and a blow has to be glancing.

The connection between Africa and the North America and the South America is presented in Figure 3. We can see very clearly that two more holes in a crust are located in the Gulf of Mexico and in the Hudson Bay. The radii of the holes in the crust of an ancient planet are 800 and $400 \mathrm{~km}$, accordingly. An analysis of contours of the continents and Greenland shows that here there were two explosions also. However, the directions of the impacts at the (1) and (2) points do not coincide. On this basis, it could be suggested a possibility of comet collapse before its approach to the proto-Earth. Could it be the other comet? The answer is no. The reverse effect of the shock wave from the point (2) on the formation of the African and South American continents can be seen in Figure 3. This contradiction is simply resolved. The points (2) and (3) are the sites of the internal explosions of comet and they are sites where the fragments of a comet were emitted from under a crust. From Figure 3 it is possible to draw a conclusion that the big piece of the comet was located under a planet crust and it lifted the continents.

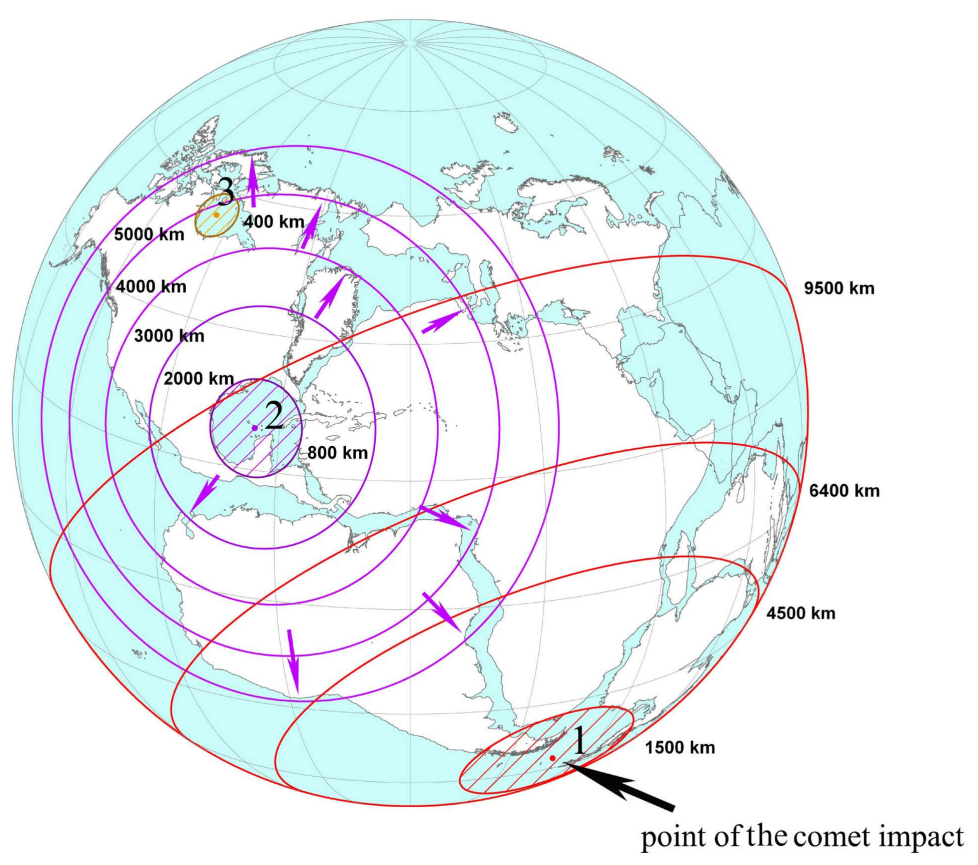

Figure 3. The result of the gluing process of South, North America and Africa was shown. The shaded circles marked the craters in the Gulf of Mexico (2) and in the Hudson's Bay (3) which have been formed as a result of explosions under the planet crust. The shock contours from the gap in the Gulf of Mexico are shown in additional. 
The gluing of Antarctica, Australia, Africa and Asia is presented in Figure 4. Also as in Figure 3 the linear faults and ring structures are well visible. Holes in the Black Sea and in the Lake Baikal in Figure 4 are not presented.

Thus, all the continents were formed at one time as a result of excessive gas pressure under the crust of the planet. Supercontinent Pangea was split from the beginning, but the platforms have not dispersed because of the increased viscosity of the magma, and also due to the fact that the excess pressure released through a break in the Pacific Ocean.

So on the surface of the Moon, unlike the Mars surface, there is not of Fe isotopes overabundance, and in the presence of the ${ }^{3} \mathrm{He}$ overabundance, it could be concluded that at the first moment under the crust the gas was exploded due to the rapid heating, and then a nuclear thermal explosion with expansion of liquid magma happened. The discrepancy between the Earth and the Moon occurred in viscous liquid phase in the form of an eight-figurative stretching of a liquid drop, with little or without emission of pieces of fused magma into the near-Earth space. The Earth's crust near a comet crash site was badly split. From the Earth two big pieces were torn off, the first piece has generated the Lunar Continent on the reverse side of the Moon, the second piece of the crust fell after 8 hours on the Earth, and it pressed and deformed a crust of the planet and created the Tibet mountain range.

\section{Water and Life Origin}

This section will be devoted to a problem of oceans and seas formation and the life origin.

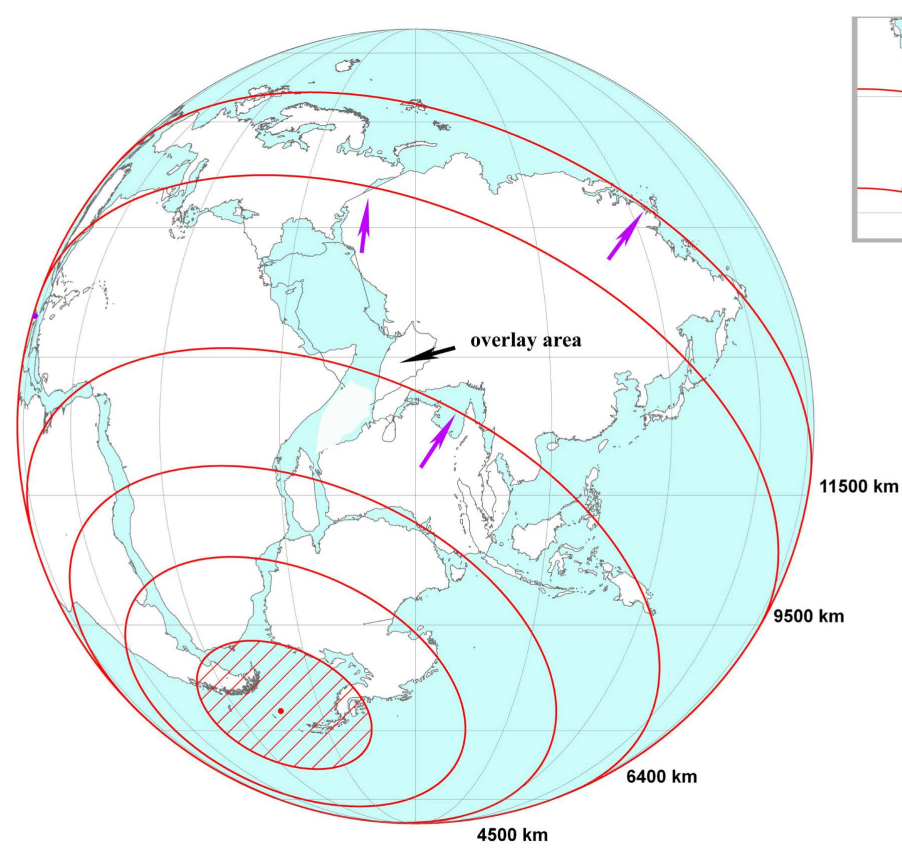

Figure 4. The result of the gluing process of Africa, Madagascar, India, Antarctica, Australia and Asia is shown. On the plate the overlapping of some pieces of the continent and their moving are presented. 
There is a lot of water on the Earth, even though on the neighboring planets Venus and Mars water in sufficient quantity is not observed. Typically, comets are consisting from different gases; even they can have water in their composition. However more often a case when the dry ice prevails in comets composition. So, the question is how to get out water from $\mathrm{CO}_{2}$ ? It's quite simple question. Water may be formed in two ways: the first one is a dissociation of $\mathrm{CO}_{2}$ molecules and a subsequent interaction with atomic hydrogen (Equation (1)). The second way is an acetate path, which includes an interaction of $\mathrm{CO}_{2}$ with $\mathrm{H}_{2}$ (Equation (2)).

$$
\begin{array}{ll}
\text { Earth core } & \Rightarrow(p-n) \Rightarrow \mathrm{H}^{+} \\
\mathrm{CO}_{2} & \Rightarrow \mathrm{CO}+\mathrm{O}^{-} \\
\mathrm{CO} & \Rightarrow\langle\mathrm{C}\rangle+\mathrm{O}^{-} \\
\mathrm{O}^{-}+2 \mathrm{H} & \Rightarrow \mathrm{H}_{2} \mathrm{O}
\end{array}
$$

where

$(p-n)$ - proton-neutron steams,

$\langle C\rangle-$ a free carbon in the diamond formation,

$$
\begin{aligned}
& \mathrm{H}+\mathrm{H} \quad \Rightarrow \mathrm{H}_{2} \\
& 2 \mathrm{CO}_{2}+4 \mathrm{H}_{2} \Rightarrow 2 \mathrm{H}_{2} \mathrm{O}+\mathrm{CH}_{3} \mathrm{COOH}
\end{aligned}
$$

In addition to water, from $\mathrm{CO}_{2}$ molecules it is possible to obtain the following chemical groups: a carboxyl group (-COOH-), an oxymethene group (-CHOH-), a methine group (-CH=), a methene group $\left(-\mathrm{CH}_{2}^{-}\right)$and a methyl group $\left(\mathrm{CH}_{3}^{-}\right)$(see Equation (3)). The reactions in (3) - (4) also describe the processes of methane obtaining and its hydration in gas bubbles under the crust and deeply in water at the bottom of lakes, seas and oceans nearby geologic breaks.

$$
\begin{gathered}
\mathrm{CO}_{2}+\mathrm{R}-\mathrm{H} \Rightarrow\left\{\begin{array} { l } 
{ \mathrm { R } - \mathrm { COOH } } \\
{ \mathrm { R } - \mathrm { CHOH } - \mathrm { R } } \\
{ \mathrm { R } - \mathrm { CH } = \mathrm { R } } \\
{ \mathrm { R } - \mathrm { CH } _ { 2 } - \mathrm { R } } \\
{ \mathrm { CH } _ { 3 } - \mathrm { R } }
\end{array} \Rightarrow \left\{\begin{array}{l}
\mathrm{HCOOH} \\
\mathrm{CH}_{3} \mathrm{OH} \\
\mathrm{CH}_{3} \mathrm{COOH} \\
\mathrm{CH}_{4}
\end{array}\right.\right. \\
\mathrm{CH}_{4}+\mathrm{H}_{2} \mathrm{O} \Rightarrow \mathrm{H}_{2} \mathrm{O}-\mathrm{CH}_{4}-\mathrm{H}_{2} \mathrm{O}
\end{gathered}
$$

Earlier the hypothesis of the origin of life in methane hydrates was expressed [88]; however, Miller's hypothesis about a life origin from $\mathrm{NH}_{4}$ can also be true, see Equation (5). A significant amount of heat is released into the atmosphere during thermal nuclear explosion, so there are no needs for a considerable amount of lightings that are necessary for $\mathrm{NH}_{4}$ molecules decomposition.

$$
\begin{aligned}
& { }^{12} \mathrm{C}+(p-n) \Rightarrow{ }^{14} \mathrm{~N} \\
& \mathrm{~N}+\mathrm{H} \quad \Rightarrow\left\{\begin{array}{l}
\mathrm{HN}- \\
\mathrm{H}_{2} \mathrm{~N}- \\
\mathrm{NH}_{4}
\end{array}\right.
\end{aligned}
$$




$$
\begin{aligned}
& \mathrm{H}_{2} \mathrm{~N}+\mathrm{CH}+\mathrm{H}+\left.\mathrm{COOH} \Rightarrow\right|_{H} ^{\mathrm{H}_{2} \mathrm{~N}-\mathrm{CH}-\mathrm{COOH}} \text { serine } \\
& \mathrm{H}_{2} \mathrm{~N}-\mathrm{CH}-\mathrm{COOH} \\
& \mathrm{H}_{2} \mathrm{~N}+\mathrm{CH}+\mathrm{CH}_{3}+\mathrm{COOH} \Rightarrow \\
& \mathrm{CH}_{3}
\end{aligned}
$$

As an example, the production of amino acids such as serine and $\alpha$-alanine from the primary elements, which resulting in TNE, are shown on Equation (6). The question on oil and gas fields also becomes obvious. From Equation (3) it follows that in southern hemisphere there will be a lot of kimberlitic pipes and not so many of the oil-gas fields, whereas in northern hemisphere will be the opposite situation (see Table 1 and Table 2). Next, we will pay attention to spatial arrangement of ores.

\section{Atomic Number Model of the Earth Inner Structure}

Thus, on the one hand it is clear that nuclear reactions were involved in process of the Earth formation with creation of $(p-n)$ couples and atomic hydrogen. On the other hand, of course, the attentive reader will be surprised how a small comet was able to

\begin{tabular}{|c|c|c|c|c|c|c|c|c|}
\hline \multirow{2}{*}{ Continent } & \multicolumn{5}{|c|}{ Geological structure of the diamond occurrence } & \multirow{2}{*}{$\begin{array}{c}\text { Total } \\
\text { deposits }\end{array}$} & \multirow{2}{*}{ Mining* } & \multirow{2}{*}{$\%$} \\
\hline & alluvial & kimberlite & primary & secondary & other & & & \\
\hline Africa & 267 & 112 & 5 & 15 & 33 & 432 & 240 & 55.5 \\
\hline South America & 207 & - & - & 266 & - & 473 & 304 & 64.3 \\
\hline Asia & 36 & 27 & 1 & 2 & 2 & 68 & 40 & 58.8 \\
\hline Australia & 13 & 11 & 25 & 4 & 14 & 67 & 33 & 49.3 \\
\hline North America & - & 31 & 1 & 3 & - & 35 & 6 & 17.1 \\
\hline Europe & 4 & 10 & 2 & - & - & 16 & 3 & 18.7 \\
\hline
\end{tabular}
penetrate the thickness of the upper and lower mantle (a distance of $\sim 2800 \mathrm{~km}$ ) and it

Table 1. The statistics of the diamond deposits, the diamond mining on the continents obtained from Gilmore et al. (2005) data.

*-Only well known diamond production of mine region, so it isn't artisan mining or small commercial scale.

Table 2. The oil and gas deposit statistics on the continents and on the shelves near to them.

\begin{tabular}{cccc}
\hline \multirow{2}{*}{ Continent } & Oil and gas geological structures in $\%$ of total deposit area & Total, \% \\
\cline { 2 - 4 } & Onshore, \% & Offshore, \% & 1.6 \\
\hline Australia & 1.1 & 0.5 & 5.4 \\
Africa & 4.0 & 1.4 & 5.2 \\
South America & 4.1 & 1.1 & 23.1 \\
North America & 19.8 & 3.3 & 28.6 \\
Europe & 20.7 & 7.9 & 36.0 \\
Asia & 31.4 & 4.6 & 99.9 \\
Total & 81.1 & 18.8 & \\
\hline
\end{tabular}


was able to start a nuclear reaction on the mantle-core boundary? It is necessary to search an answer in the revision of the Earth structure.

As well known, that the Earth's crust consists mainly of oxides of light elements such as $\mathrm{SiO}_{2}$ (59.71\%), $\mathrm{Al}_{2} \mathrm{O}_{3}$ (15.41\%), $\mathrm{CaO}$ (04.90\%), $\mathrm{MgO}$ (4.36\%), $\mathrm{Na}_{2} \mathrm{O}(3.55 \%), \mathrm{K}_{2} \mathrm{O}$ (2.80\%), $\mathrm{H}_{2} \mathrm{O}(1.52 \%)$. The exception makes only oxides of $\mathrm{Fe}(z=26)$ and $\mathrm{Ti}(z=22)$, which content in the crust is equal to $\mathrm{FeO}(3.52 \%), \mathrm{Fe}_{2} \mathrm{O}_{3}(2.63 \%)$ and $\left(\mathrm{TiO}_{2} 0.60 \%\right)$, respectively [89] [90]. Heavy elements are absent in the Earth crust in a significant amount. It allows to draw a conclusion that the elements were separated in the melted magma and core. In addition, the presence of iron in the crust permits to estimate an aim parameter of a comet impact.

For this purpose, we will compare the Moon volume (Equation (7)) with volume of a spherical segment of the Earth (Equation (8)) and we will find a segment height $h_{e}$ :

$$
V_{m}=\frac{4}{3} \pi r_{m}^{3}
$$

where

$$
\begin{array}{r}
r_{m} \text {-average Moon radius, } V_{m} \text {-volume of Moon } \\
\qquad V_{s}=\pi h_{e}^{2}\left(R_{e}-h_{e} / 3\right)
\end{array}
$$

where

$$
\begin{aligned}
& V_{s} \text { - proto-Earth segment volume, } \\
& h_{e}-\text { segment height, } \\
& R_{e} \text {-average radius of proto-Earth. }
\end{aligned}
$$

The solution of Equation (7) and (8) shows that the height of a spherical segment is approximately equal to $1050 \mathrm{~km}$. Thus, due to flotation the iron layer should be located slightly below this level, at a depth of $\sim h_{e^{*}}$ On the other hand, light elements, such as $\mathrm{Na}, \mathrm{Mg}$ and $\mathrm{Al}$, should be located at a small depth, immediately under the crust, i.e. at a depth of about $100 \mathrm{~km}$.

Let's note that boundary layers, such as Upper-Lower mantle boundary, Gutenberg discontinuity, Lehmann-Bullen discontinuity located on depth of 660, 2860 and 5160 $\mathrm{km}$, accordingly. Based on the fact that the main fuel elements are ${ }^{40} \mathrm{~K},{ }^{137} \mathrm{Cs},{ }^{232} \mathrm{Th},{ }^{235} \mathrm{U}$, ${ }^{238} \mathrm{U}$ with the numbers $19,55,90$ and 92 , it is possible to assume that the depth of elements sinking into magmas and core linearly depends from an element number. Then we can derive the following equation relating the depth of element sinking (see Equation (9)).

$$
\operatorname{depth}(\mathrm{km})=A+B z
$$

where

$z$-atomic number, $A=566 \mathrm{~km}, B=-63.58 \mathrm{~km}$ per atomic number.

The dependence of the depth of elements sinking from an element number is presented in Figure 5.

The basic fuel elements such as ${ }^{40} \mathrm{~K},{ }^{232} \mathrm{Th},{ }^{235} \mathrm{U},{ }^{238} \mathrm{U}$ are shown in Figure 5 additionally. Recall that the thermal emissions of ${ }^{232} \mathrm{Th},{ }^{235} \mathrm{U},{ }^{238} \mathrm{U}$ are equal to $9.46 \times 10^{-5}, 5.69 \times$ $10^{-4}, 2.64 \times 10^{-5} \mathrm{~W} / \mathrm{kg}$, respectively (see [91]). The half-lives of ${ }^{232} \mathrm{Th},{ }^{235} \mathrm{U},{ }^{238} \mathrm{U}$ are equal 


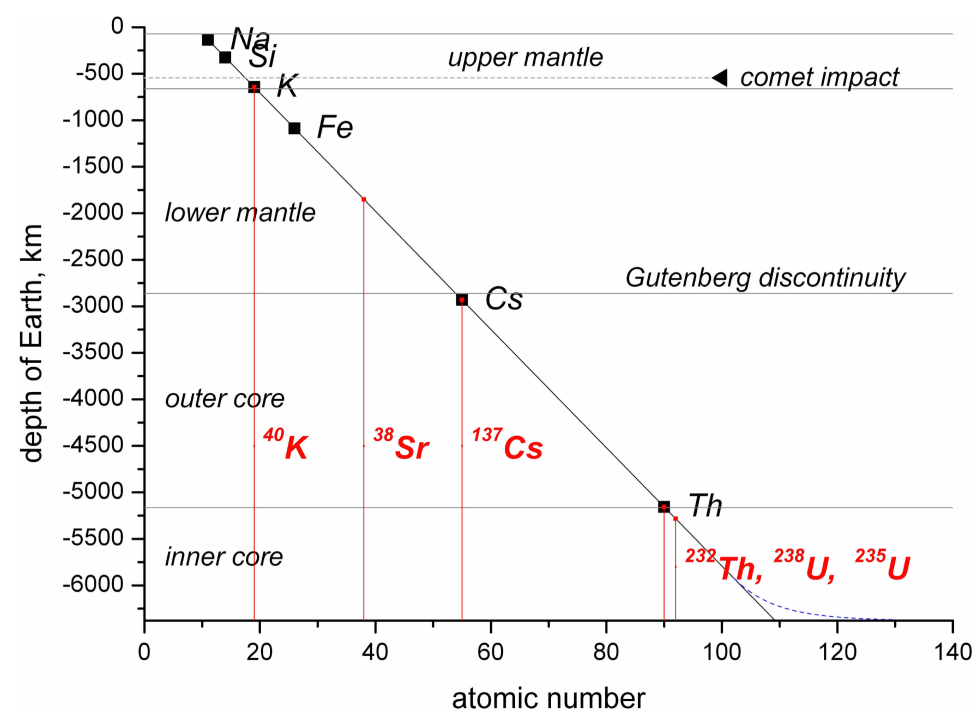

Figure 5. The linear dependence of the element sinking depth in the molten magma and in the core from the element number is presented. The red lines show the basic fuel nuclear elements, such as ${ }^{40} \mathrm{~K},{ }^{232} \mathrm{Th},{ }^{235} \mathrm{U}$ and ${ }^{238} \mathrm{U}$.

to $14.01,0.704,4.468 \mathrm{Ga}$, respectively [92]. From Figure 5, it is clearly visible that the ${ }^{232} \mathrm{Th},{ }^{235} \mathrm{U},{ }^{238} \mathrm{U}$ are present on the boundary between the outer and inner cores, corresponding to Lehmann-Bullen discontinuity. The border between an upper and a lower mantle coincides with the depth of sinking of the third largest fuel element, such as a ${ }^{40} \mathrm{~K}\left(2.92 \times 10^{-5} \mathrm{~W} / \mathrm{kg}\right)$, having a half-life period of $1.25 \mathrm{Ga}$ years.

Let's notice that the distribution of iron atoms is at a depth of $1087 \mathrm{~km}$ that is in agreement with the above estimation of the height of a spherical segment (see Figure 5). The light nucleus, those are results of nuclear chain reactions, quite the contrary float up. An additional the Gutenberg level, between the lower mantle and outer core, corresponds exactly to the level of ${ }^{137} \mathrm{Cs}$ sinking. However, by nuclear reactions, sinking the ${ }^{38} \mathrm{Sr}$ elements had to be formed, but this level of discontinuity has not been found yet. The maximum number of the element near of the planet center, on the depth of $6300 \mathrm{~km}$, is equal to $\sim 108$ that probably specifies on the fundamental nature of the offered element number model of the Earth (ENME).

As well known the elements with the numbers ${ }^{93} \mathrm{~Np}$ (Neptunium) and ${ }^{94} \mathrm{Pu}$ (Plutonium) were found in the Earth's crust in trace concentrations. The elements from ${ }^{93} \mathrm{~Np}$ to ${ }^{101} \mathrm{Md}$ were obtained in the nuclear reactors, and the elements with numbers in range 102 - 115 (118) were created by accelerating of the particles.

Due to the fact that some elements were thrown on the Earth's surface during the Moon formation, it is interesting to check, whether preserved in the crust elements, which are distributed linearly according to their numbers. The data [89] were used for this purpose.

Undoubtedly, elements, with numbers lower 26, will be strongly mixed because of comet impact. In addition, some elements will not satisfy the linearity condition due to radioactive decay. However, such elements in the Earth's crust could be found. 
The linear relationship between $\mathrm{Ga}, \mathrm{As}, \mathrm{Mo}, \mathrm{Te}, \mathrm{Ce}$, Dy and Er content in the crust and the element number is shown in Figure 6. The atomic numbers of these elements are $31,33,42,52,58,66$ and 68 . The correlation coefficient $\mathrm{R}$ is equal to -0.998 , i.e. $\mathrm{R}^{2}$ (0.996) is very close to 1 . However, most of the elements have undergone a strong radioactive decay. An example of the exponential distribution of content elements in the crust of their atomic number is presented in Figure 7. These elements are Se- $\mathrm{Zr}-\mathrm{Ba}-\mathrm{Pt}$ with atomic numbers (34-40-56-78) and Ge-Y-Pd-I with atomic numbers (32-39-46-53).

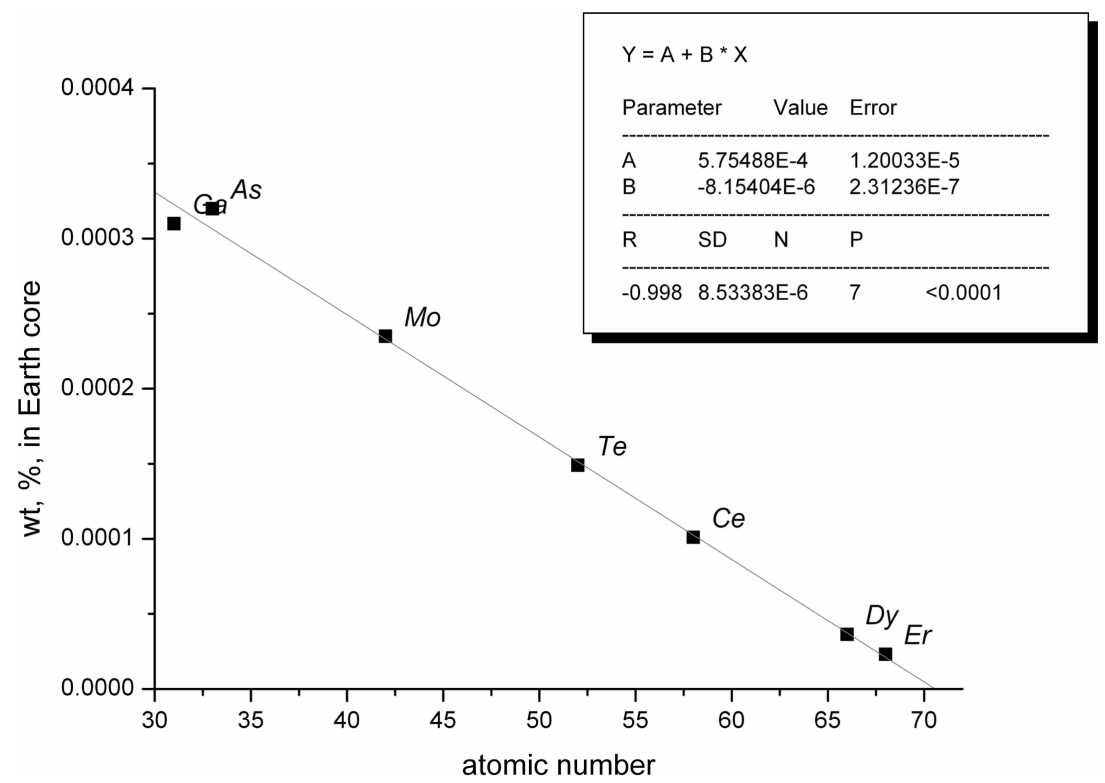

Figure 6. The linear dependence of the volume content of some elements in the Earth's crust from their element number is presented.

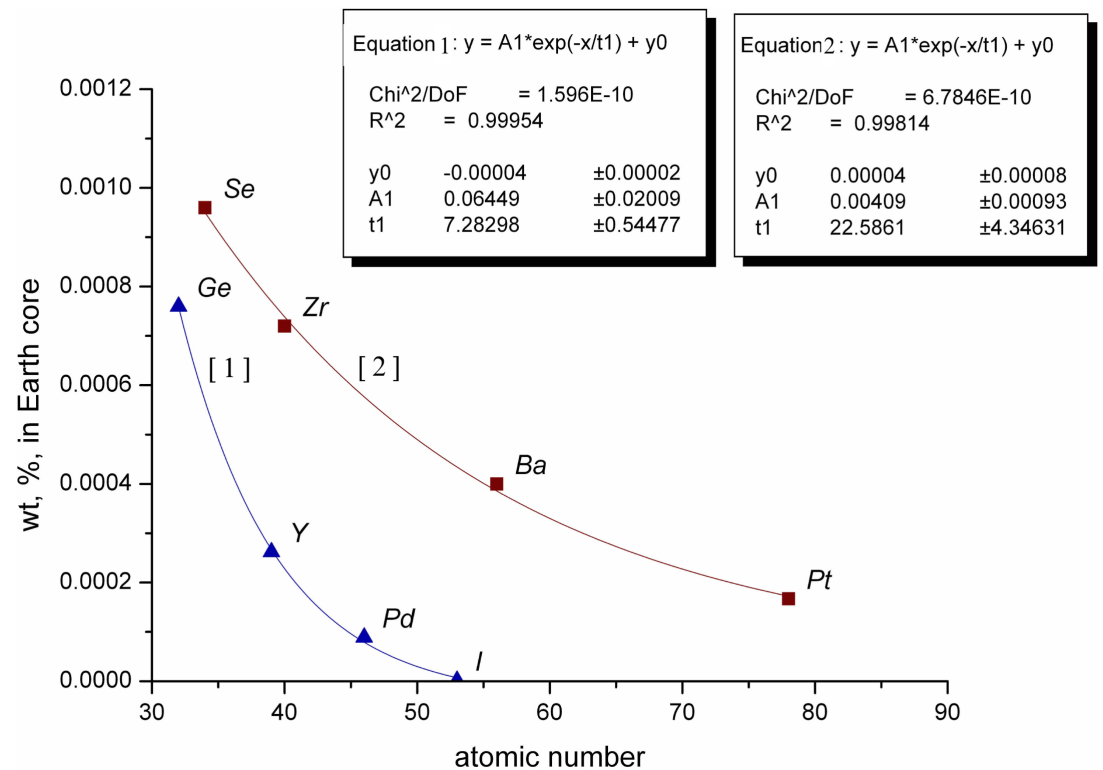

Figure 7. The exponential dependence of the volume content of some elements in the Earth's crust from their element number is presented. 
The square of the correlation $\mathrm{R}^{2}$ of these elements is equal to 0.999 , and 0.998 , respectively. Thus it is clear that the ENME model, which does not consider a radiating decay at flotation of elements, is a rough model that is fair only as a first approximation.

Thus, the chemical compounds including such elements as $\mathrm{Fe}, \mathrm{Pb}, \mathrm{Zn}, \mathrm{Th}, \mathrm{U}$, and other heavy elements with $z>50$, can be remained on the Pangea surface after splash out of core material over the edge of continent. Moreover, the heavy elements could be stuck in breaks between the continents. The parts of Africa and Australia can serve as such example. On the other side, the heavy elements that have remained after the comet impact in the upper liquid magma, again gradually sank deeper into the planet. Due to the fact that the impact of a comet was on the level higher the level of Fe immersion, there is no dense coating of the earth surface by the iron oxides, as it is observed on Mars.

We have replaced crust-mantle-core structure of the Earth by the discrete layered nuclear structure, in which the first nuclear layer of ${ }^{40} \mathrm{~K}$ lies on depth only $600 \mathrm{~km}$. Then the understanding of subduction zones and reasons of continental drift obtains absolutely other physical sense. Moreover, it is easy to see that the convective processes in "magma" (100 - 2800) km will be suppressed due to temperature inversion on discrete nuclear layers.

In general, such conclusion about depressed convection processes could be made earlier as nuclear reaction products from the border of the mantle-core are not observed at volcanic eruptions emissions.

Let's summarize this section. Just imagine that your starship approaches to an unknown Star. Your mission is to build a habitable space base. Space navigator asks you how to redirect a comet of this Star. You need to choose a suitable planet and to specify precisely a place on this planet for comet impact. It could be recommended to select a planet with crust of $30-40 \mathrm{~km}$ thick and to strike it at a tangent to its surface, with the aim of a distance equal to the depth of sinking ${ }^{40} \mathrm{~K}$.

\section{The Spatial Distribution of Kimberlites as of Shock Stress Markers}

In this section, we investigate how a small comet lifted up the pressure under a protoEarth crust.

As it is well known, diamonds are formed at high pressures in kimberlitic pipes [93]. However, for a long time, researchers asked a question: why kimberlites were found only in the inner parts of the platform, which have a thickness of about $40-60 \mathrm{~km}$, and which are characterized by high stability and strength. At the same time in the ocean bottom areas, where the crust thickness is equal $\sim 10 \mathrm{~km}$, holes in the crust do not occur. Furthermore, there is no formation of kimberlite pipes in the active geological zones, where there are breaks and crust shifts, as well as in volcanic activity areas. The answer to this question in a modern geology does not exist.

Also we will notice that the inclusion of various carbonates and bicarbonates were recorded in the natural diamonds. The compounds of $\mathrm{CaSiCO}_{3} / \mathrm{CaCO}_{3}$ were found in 
diamonds from Juina area at southwestern Brazil [94] [95] [96] (see also early study about present mineral inclusions in diamonds in the Sputnik kimberlite pipe, Yakutia, Russia [97]). In [94] [95] [98] and [99] it was confirmed that some diamonds might been formed as a result of subduction of crustal material to a depth of at least the lower transition zone or perhaps even in the lower mantle. Chemical compounds of $\mathrm{CaMg}\left(\mathrm{CO}_{3}\right)_{2}$ were detected in samples of Rio Soriso Brazil [100], in Mato Grosso State, Brazil [101] and in the Collier-4 pipe, Brazil [102]. The $\mathrm{FeCO}_{3}$ is much less common in diamonds. These compounds were found in the field of Kankan, Guinea [103].

In [100] it was pointed on a fact that diamonds may be generated from the depth more than $580 \mathrm{~km}$. In [104] it was noted that lower-mantle minerals resemble those, which included in diamonds, were created under ultra-high pressure conditions (20$25 \mathrm{GPa}$ and higher), corresponding to depths of $500-600 \mathrm{~km}$ and greater (For details also see review [104]).

The calcium presence in diamonds testified that the layers of the upper magma with depths of sinking $\mathrm{K}$ and $\mathrm{Ca}$, i.e. $~ 600-700 \mathrm{~km}$ have been actually involved in process of diamonds formation. It is in agreement with diamonds depth described above. We can assume that it was due to the perturbation of the heat layer of ${ }^{40} \mathrm{~K}$ and streaks appeared which look like solar prominences. These plasma jets burned pipes in powerful native platforms.

\subsection{General Statistics of Diamond Distribution on the Continents}

The general statistics on distribution of diamonds on continents is shown in Table 1. From statistics, it is clear that the amount of diamond deposits in southern hemisphere is an order greater than in northern hemisphere. For example, in North America the amount of diamond deposits in 12.3 times less than in Africa.

From this statistics it follows that in the southern hemisphere a pressure in geological layers was significantly greater than in the northern hemisphere. Currently there are no any geological theories that explain the abnormally high pressure in the geological layers in a southern part of Africa.

\subsection{The Spatial Distribution of Diamond Deposits}

It is interesting to consider the spatial distribution of diamond deposits. As it is seen from Table 1, when moving from the southern part of Africa, the density of diamond deposits decreased and its spatial distribution is non-uniform. Below it is shown that the distribution of kimberlite pipes formed linear and circular structures. Considering this issue in more details, we will gradually pass from a simple case to case that is more difficult.

\subsubsection{The Diamond Structures in India, South-East Asia and China}

The distributions of kimberlite pipes in India, South-East Asia and China are shown in Figure 8. The kimberlite deposits form two ring structures and two linear structures. In Asia, the two gas-bubbles structures can be singled-out: one in India, other in Indonesia, with a diameter of 630 and $900 \mathrm{~km}$, respectively. Let's note that the depositions on 


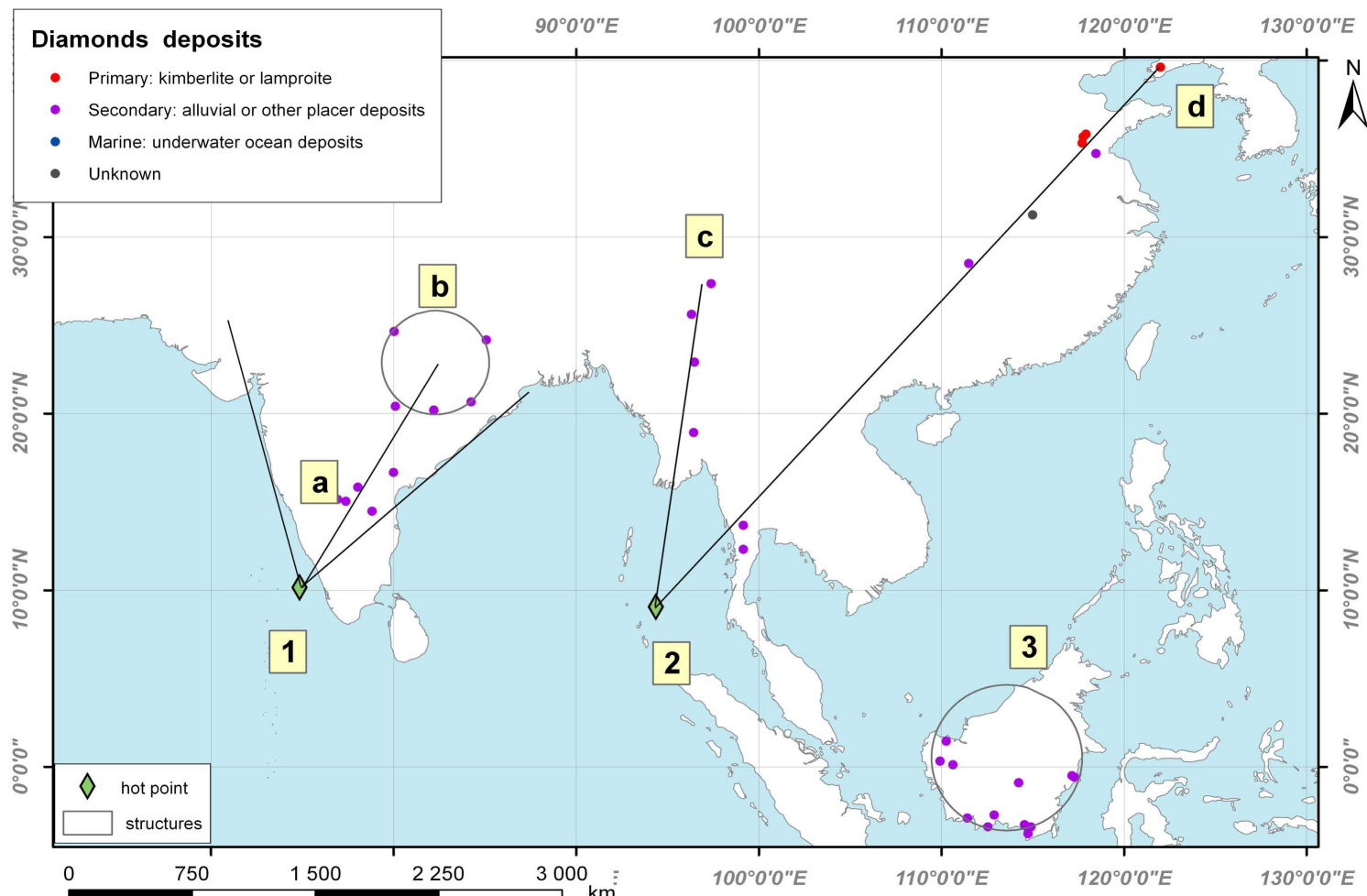

Figure 8. The kimberlite, lamproite, alluvials deposits and underwater ocean diamond deposits in India, Southeast Asia and China are displayed by color marks. The linear and circular structures and diamond hot spots (with number 1 - 2) are marked in figure in addition.

lines (c) and (d) have exceptionally strongly pronounced linearity and regularity in a relative positioning. Thus in China, rough periodicity of an arrangement of diamond deposits is observed: (Yuan R. Area. $28.5^{\circ} \mathrm{N} .111 .5^{\circ} \mathrm{E}$ ), (Dabie Shan Mountains, $31.25^{\circ} \mathrm{N}$, $\left.115^{\circ} \mathrm{E}\right)$, (Tancheng area, $34.73^{\circ} \mathrm{N}, 118.47^{\circ} \mathrm{E}$ ) and (Wafangdian, $39.62^{\circ} \mathrm{N}, 122^{\circ} \mathrm{E}$ ).

In India, the linear structure is more complex and is formed from the contours of the continent and the line to the center of the circular structure. On Borneo the kimberlite pipes are formed a pure ring structure, which is coinciding with the contours of the island. Thus, on the example of Borneo, we can see that diamond genesis is directly related to formation of continents. The tremendous pressure, which has led to a split in the planet's crust, created the conditions for emission of carbon dioxide and derivatives, which resulting from the interaction of $\mathrm{CO}_{2}$ with a ${ }^{40} \mathrm{~K}$ plasma spear and melted above ${ }^{40} \mathrm{~K}$ mantle layers inside of the kimberlite pipes. The linear structures were formed as a result of abrupt motions of the gas-bubble on the inner side of the planet's crust.

The ring structure ((b) in Figure 8) allows to estimate the gas-bubble speed under the planet crust. As Tibet does not show of volcanic activity, it can be assumed that it is a piece of the Moon, which had fallen back to Earth. Taking into account, an initial position of Tibet, as well as position of a break in the Pacific Ocean, it is possible to draw a conclusion that this piece of the planet's crust was in space during approximately eight hours. The fallen fragment deformed a planet crust, than prevent the further linear ad- 
vancement of the gas-bubble. Taking into account that the gas-bubble past from the southern extremity of Africa the distance equal to $4000-5000 \mathrm{~km}$, it is possible to concluded that the gas-bubble velocity in a mantle under the crust of the planet was equal to $500-600 \mathrm{~km} / \mathrm{h}$. Let's note that a speed of gas through the kimberlite pipes is equal to $\sim 200 \mathrm{~km} / \mathrm{h}$, i.e. it is comparable with a gas-bubble speed.

\subsubsection{The Diamond Structures in Australia}

Diamond deposits distribution in Australia are shown in Figure 9. Unlike South East Asia the diamond distribution in Australia formed pronounced impact ring structures, which correspond to two powerful explosions under Australia continent. The shock waves of the gas-bubbles structures extend from epicenters of the explosions with formation of the shock contours. The outer contours of the gas-bubble structures coincide with contours of the Australian continent (see (b), (c), (d) in Figure 9). This is particularly clearly seen in the outer contour of the right ring of the kimberlite pipes distribution.

\subsubsection{The Diamond Structures in North America and Europe}

From Figure 10, it is clear that power of explosive processes under the North America was not enough for the formation of numerous of kimberlite pipes. As you can see from Figure 10, some deposits appeared as a result of an interference of shock waves generated from the linear and circular structures. In the center of the (1) and (2) circular

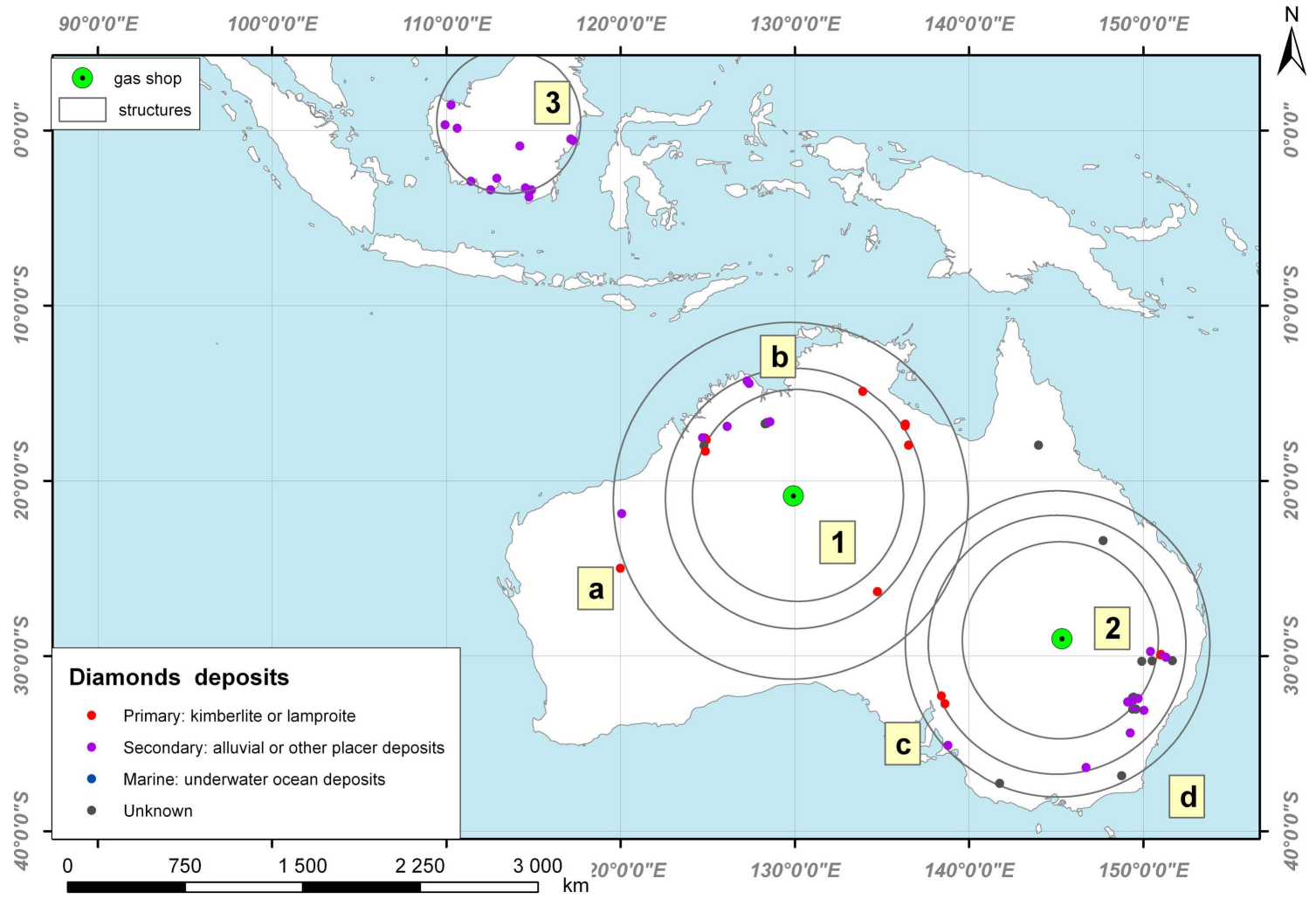

Figure 9. The kimberlite, lamproite, alluvials deposits and underwater ocean diamond deposits in Australia are shown. In addition the displayed linear and circular structures (with number 1 and 2) are marked. 


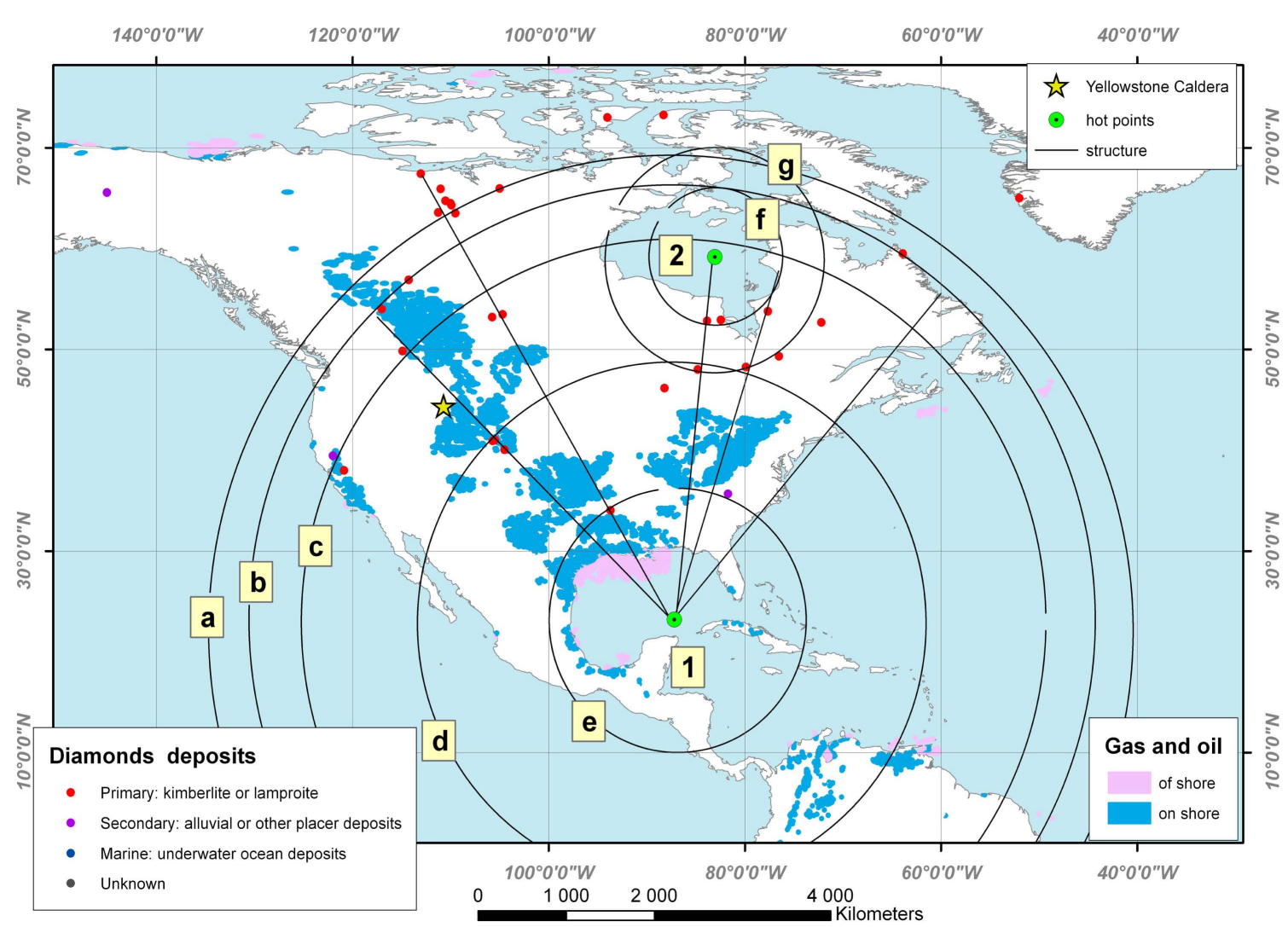

Figure 10. The deposits of kimberlite in the North America, linear and circular structures drawn from the crater in the Gulf of Mexico, and Hudson Bay are shown. In addition, the positions of the Yellowstone Caldera and gas-oil deposits are shown.

structures are holes in the crust, which was not observed in the case of Australia. The gas-bubbles just brook through the crust surface of the protoplanetary. It was in time of formation of North America continent, approximately twenty hours after comet impact, and a crust surface was softened after the activation of the planet's core. Thus, Mexico, and Hudson Bay are the results of the fast lifting and subsequent creation of a gap in a crust by gas-bubbles. Let's note that previously it was dominated opinion that gulfs were generated in result of meteorites falling. In process of removal from the (1) epicenter the attenuation of shock waves is observed.

In the European part of Russia and in Scandinavia there are not many the kimberlite pipes and so it was not easy to allocate the kimberlite structures (see Figure 11(a)). Possibly the center of the ring structure was located in a break in the Black Sea. In the central part of Russia sedimentary rocks cover the kimberlite deposits and no one tried to look for kimberlites. The several pipes in this area were found on the ring (a). In the European part only one linear structure could be pointed out by using four points. In the Eastern Siberia (Figure 11(b)), it is possible to allocate three linear structures. One of the contours of a circular structure coincided with contours of the Lake Baikal. However, the geological data of kimberlite deposits in Eastern Siberia are insufficient in order to make some unambiguous conclusions. 

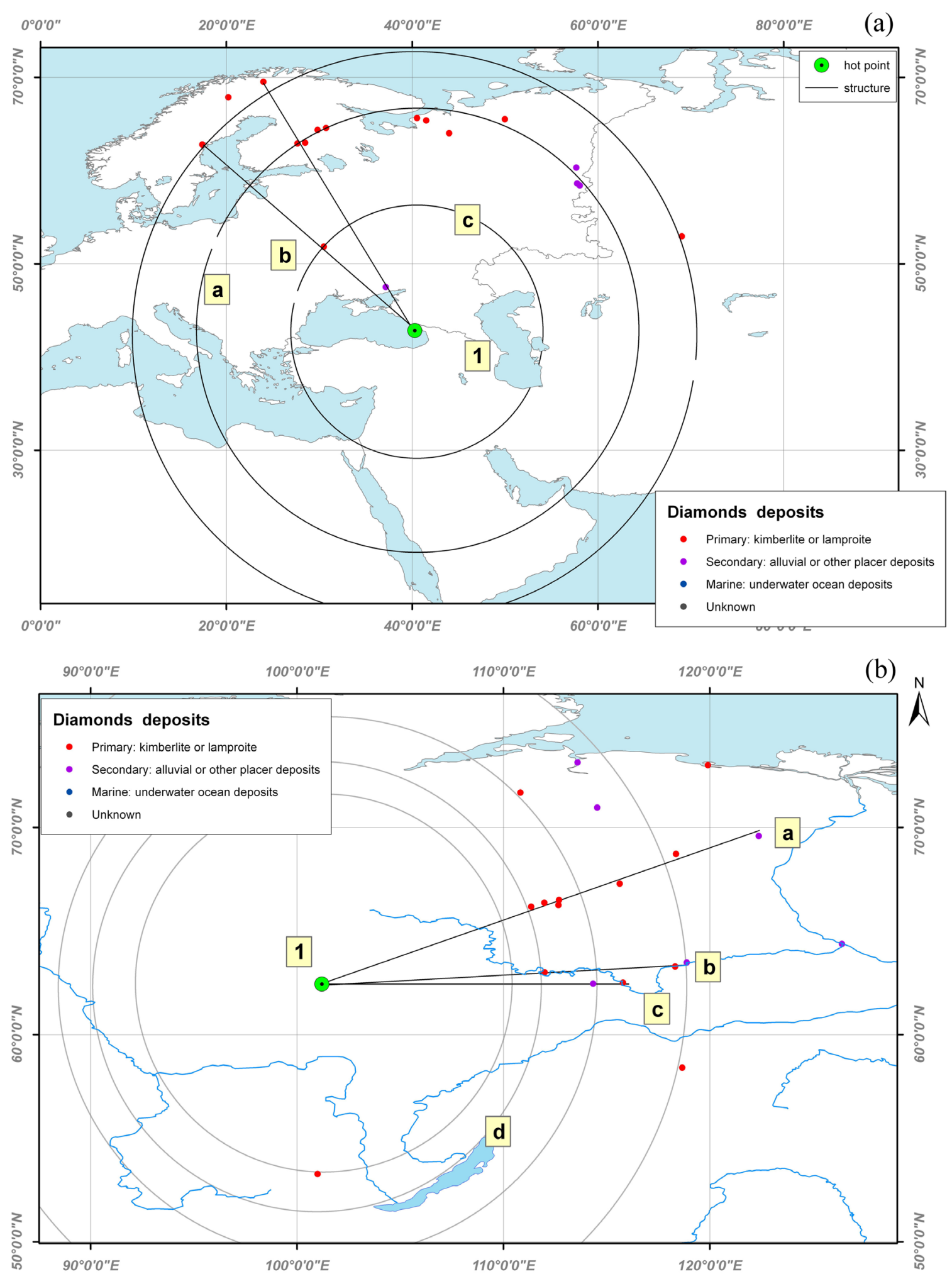

Figure 11. The linear and circular structures and kimberlite deposits in Europe (a) and in Siberia (b) are displayed.

\subsubsection{The Diamond Structures in Africa and in South America}

The analysis of the linear and circular structures in South America and in Africa is the 
most difficult. There are many kimberlite pipes on these continents and at first it seems that they are located chaotically. The linear and circular structures of kimberlite deposits in South America are shown in Figure 12. It was possible to identify two full circular structures marked in Figure 12 as (1) and (2) and the segment of the third circular structure (3). In contrast to North America in the middle of the ring structures ((1) and (2)) there are no gaps, so at the moment of South America formation, the planet crust was rigid enough and the pressure under a continent was higher than at the moment of North America formation.

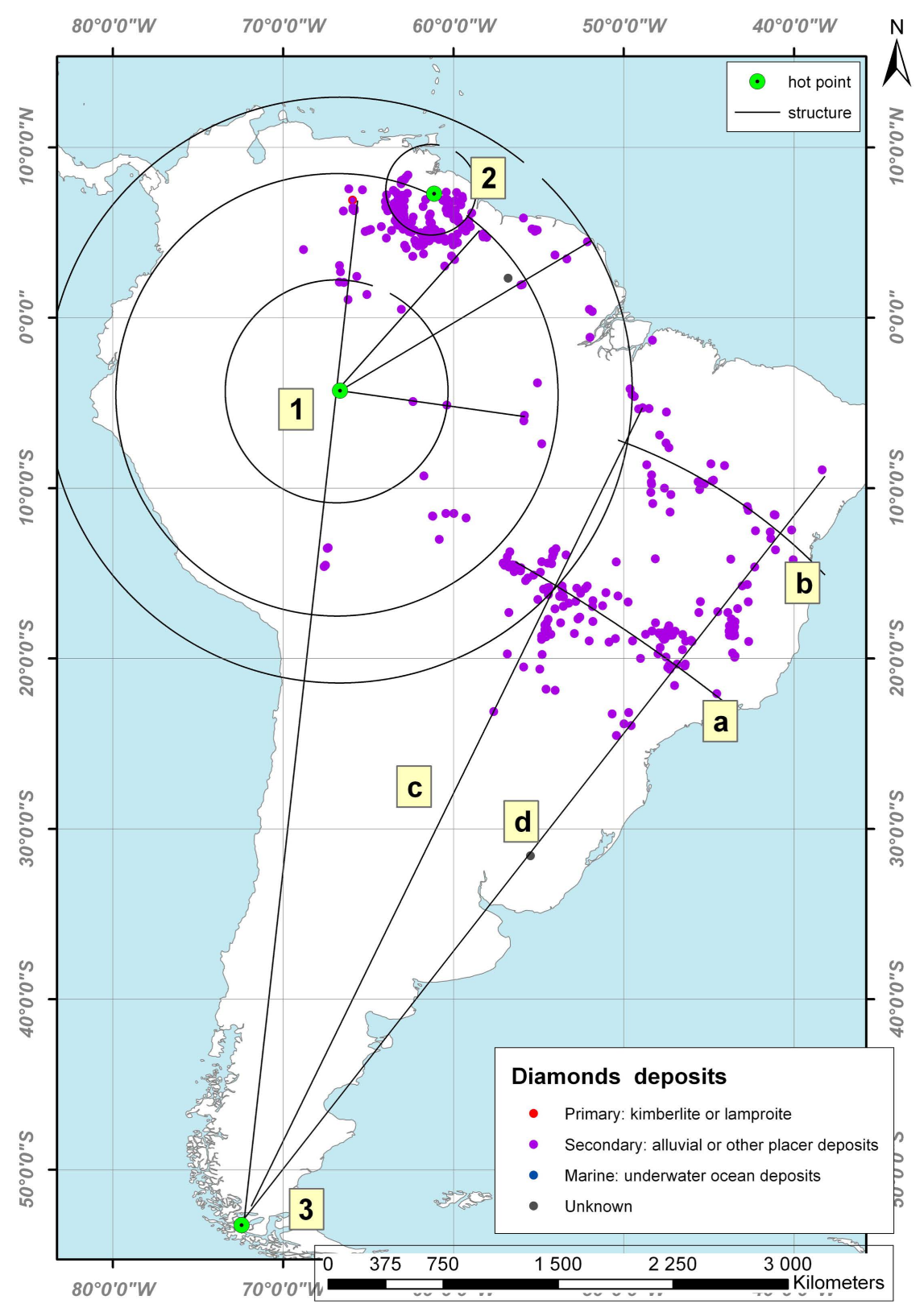

Figure 12. The kimberlite, lamproite, alluvials deposits and underwater ocean diamond deposits in the South America are shown. The linear and ring structures with the centers of the points which designated as $1-3$ are presented. 
The big gas-bubble in the north of the South America led to the lifting of this part of the continent (see Figure 12). The contours of the circular structure coincide with the contours of the continent. The continuation of the lines (1) and (2) specifies a place of the Moon separation in the south part of the Pacific Ocean. However, there is a question: why in the southern part of the continent between the lines (c) and (d) there are no kimberlite deposits? It is clearly seen from Figure 12 that a pressure was enough to form the contours of the continent, but why the pressure was not enough for the formation of kimberlite pipes? Most likely, nobody is looking for kimberlite pipes in the southern part of the South America.

In the North Africa, the circular structures of kimberlite deposits are presented in Figure 13. One large circular structure and a small structure at Sahara Eye (called also as Richat Structure) are located. The third contour of the large structure coincides with the continent contours. The diameters of the rings are 2980, 2210 and $1630 \mathrm{~km}$, i.e. the circular structures are spaced apart by $325 \mathrm{~km}$. This gas-bubble structure corresponds to the West African Craton. Let's note that the distributions of deposits in northwestern part of Africa (Guinea, Cote d'Ivoire, Liberia and Sierra Leone) are complemented by distribution of deposits in the northeastern part of South America (Guyana, Venezuela). On the plate of Figure 13 a satellite image of the central part of Richat Structure $(\sim 1200 \mathrm{~km})$ a bubble structure is shown. The shock wave ring structures are clearly

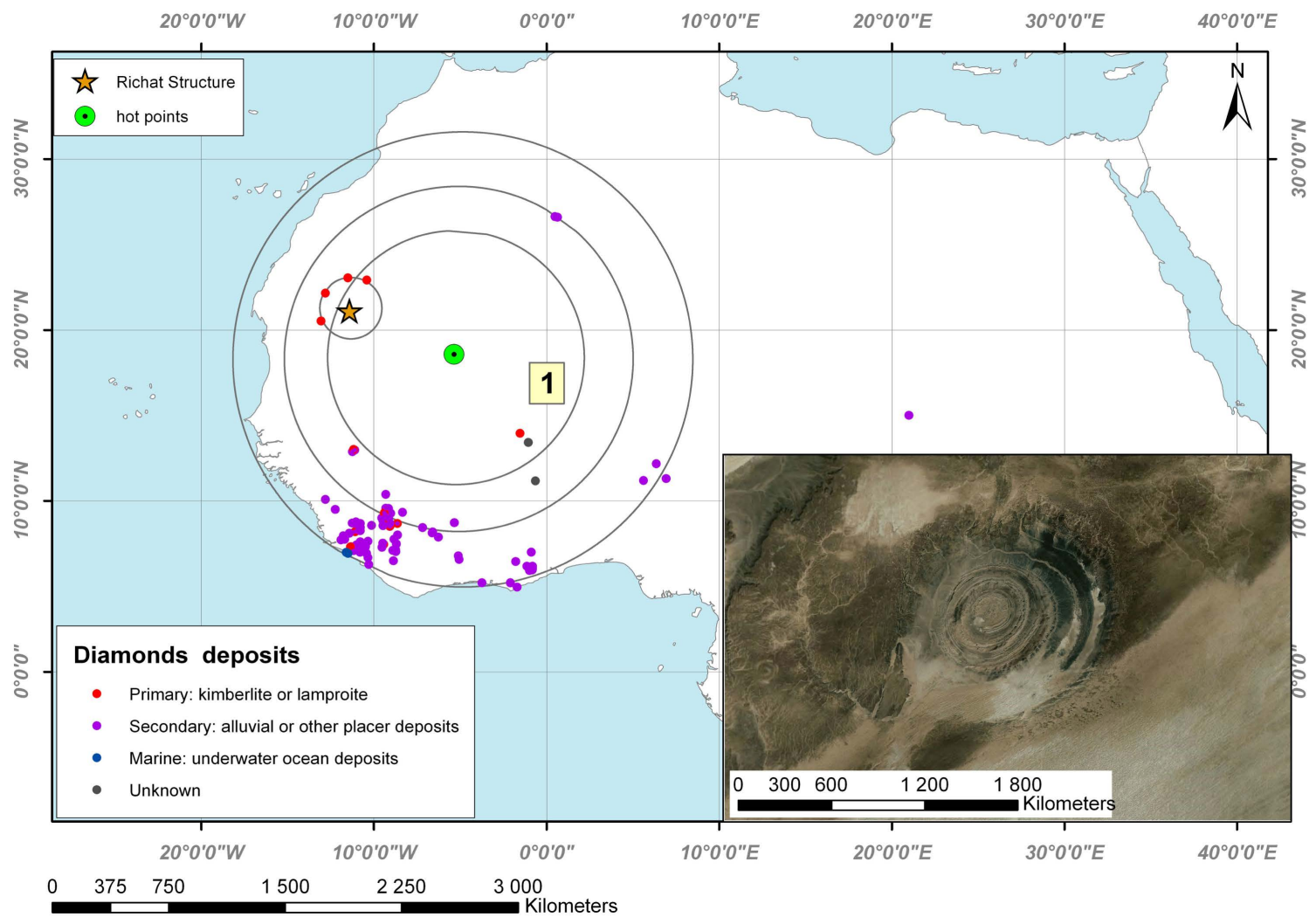

Figure 13. The linear and circular structures and kimberlite deposits in North Africa are presented. In addition the center of the ring structure of the Richat Structure is shown as an asterisk. On the plate the satellite image of the Richat Structure is shown. 
visible on the picture.

In Southern Africa (Figure 14) the powerful 4-ring structure with a diameters of $3540,2740,2060$ and $1100 \mathrm{~km}$ is allocated. Thus, the gap between the rings is equal approximately $400 \mathrm{~km}$. The third ring of a gas-bubble structure in Southern Africa partially repeats a contour of the continent. Let's note that the bubble structure in the south of Africa corresponds to the Kalahari Craton. In equatorial Africa the circular structures are poorly expressed and they have diameters of 1780 and $1080 \mathrm{~km}$, i.e., the

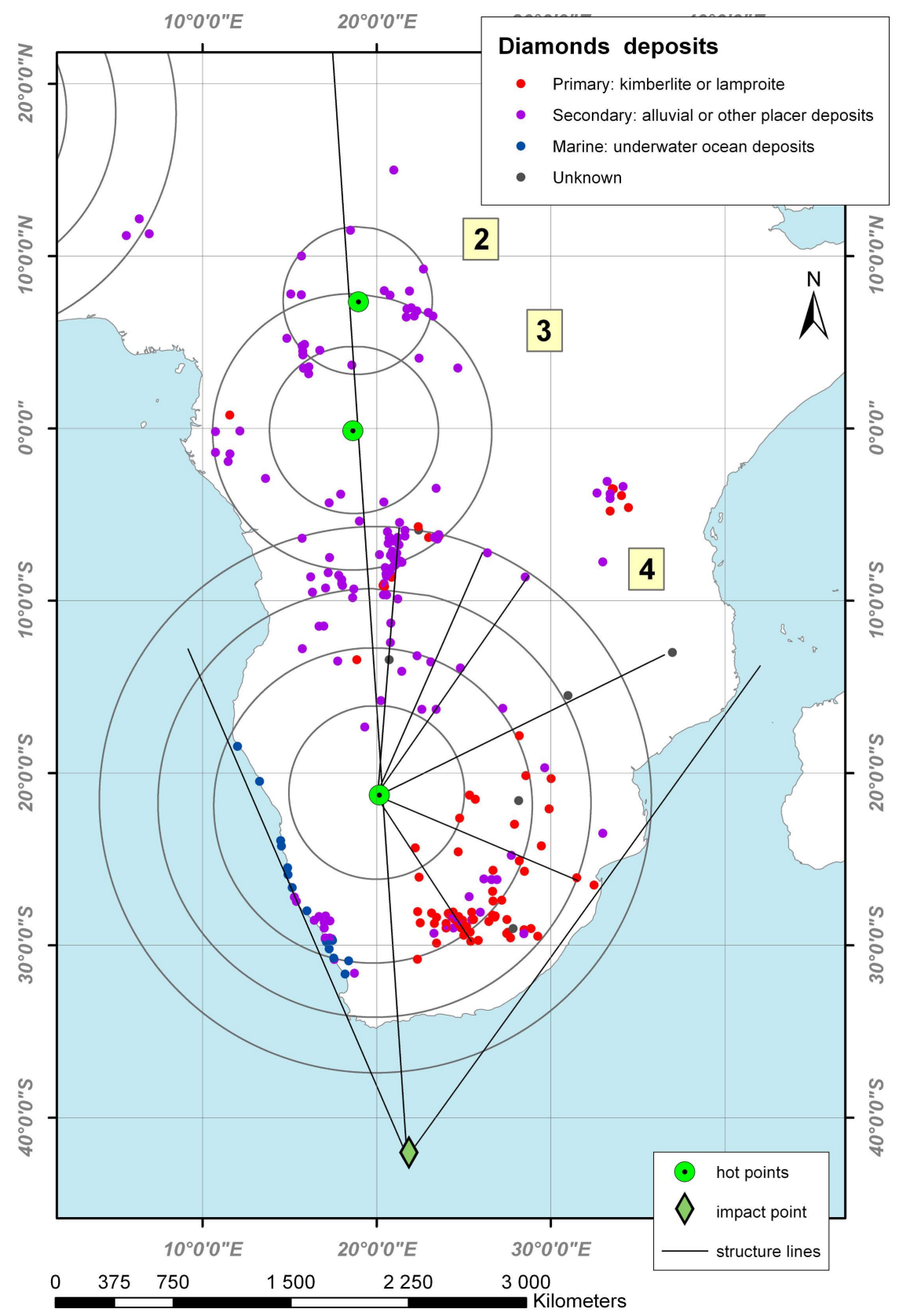

Figure 14. The kimberlite, lamproite, alluvials deposits and underwater ocean diamond deposits in Southern Africa are presented. The linear circular structures and a place of a comet impact are designated. 
gap between the rings is equal $\sim 350 \mathrm{~km}$. The gas-bubble structure partially corresponds to Congo Craton.

\subsubsection{Discussion of the Spatial Distribution of Kimberlite Pipes}

On the one hand, the locations of kimberlite deposits indicate that they were formed at the same time as a result of gas explosive processes with activation of ${ }^{40} \mathrm{~K}$ nuclear layer. On the other hand, it could be noted that the diamond genesis occurred at a time when the continents were not yet separated. Nearby the point of the comet impact the circular gas-bubble processes were dominated, while far from the impact point the linear processes were prevail. All processes took place in the upper mantle with depth $<650$ $\mathrm{km}$ in an area under a crust, in which the large fragment of the comet consisting from frozen carbon dioxide was entered. We can clearly see the reflection of gas bubbles from the bottom of the crust and the deceleration of their promotion to the border with the crust and upper mantle.

\section{The Moon as a Piece of the Proto-Earth}

\subsection{Analysis of a Lunar Topography}

If the surface of the Earth has undergone such a strong TNE impact, it is of interest to analyze ULCN-2005 the topography of the Moon. We will highlight the continent contours on the Moon by filling up a virtual Great Lunar Ocean. For this purpose, we will fill the all levels below zero meters with blue color. The topography of the Moon above the Great Lunar Ocean level is shown in Figure 15(a), Figure 16(a) and Figure 17(a). The Moon side turned to the Earth is presented in Figure 15. The reverse side of Moon is presented in two different projections in Figure 16(a) and Figure 17(a).

As well as for the Earth during formation of Pangea, the visible side of the Moon is almost completely covered by a Great Lunar Ocean; while the opposite side is completely consist of the Lunar Continent. It is important to note that the huge lunar crater with the radius of $1230 \mathrm{~km}$ is visible on the reverse side of the Moon (see Figure 16(a)). The center of the crater is located near the Lunar South Pole with the coordinates $\left(59.99^{\circ} \mathrm{S}, 179.98^{\circ} \mathrm{E}\right)$. The profile of the ULCN-2005 and Kaguya altitudes along line (1) from the crater center to the north is shown in Figure 16(b).

The reverse side of the Moon in a projection that is convenient for conjunction with the Earth surface is shown in Figure 17. Sites of connections with the Earth's continents are highlighted on Figure 17(a). Such relative positioning of continents on Earth and Moon indicates that the Earth and Moon separation had mostly liquid-drop character, instead of fragmental explosive character as it is often perceived in result of modeling of the processes of the comet impart to proto-Earth.

A comparison of topographies ULCN-2005, which is presented on Figure 15(a) and Figure 16(a), shows clearly that the visible side of the Moon is almost below a zero level. That fact clearly demonstrates bimodal behavious of Moon topography. Within the framework of the existing models, in particular by model of the great impact with Thea (GIH hypothesis), or by model of evaporation and condensation, it is impossible to explain such bimodal distribution. 

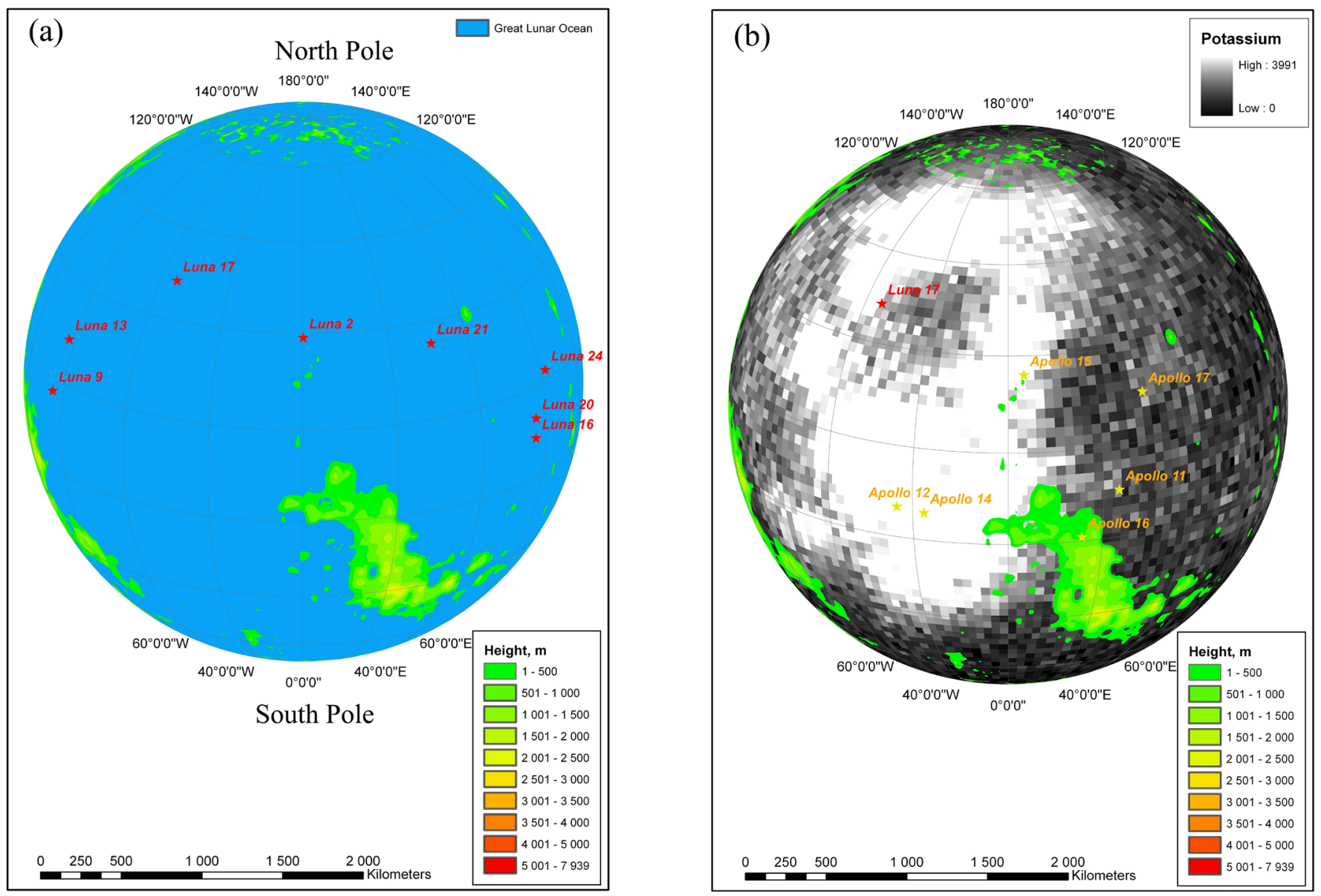

Figure 15. (a) The topography of the visible side of the Moon zero meters above according to ULCN-2005 is shown. The level, which is below 0 m, was filled by blue color and represented as a virtual Great Lunar Ocean. The positions of the Luna space stations were marked as a reference point of the Moon side in additional. (b) The potassium distribution on the visible side of the Moon is shown. The presence of an "umbilical ring" nearby Luna-17 proves a liquid-drop character of the Earth-Moon separation. The positions of the Apollo space stations were marked additionally.

\subsection{The Thorium and Iron Spatial Distribution near to a Huge Lunar Crater}

In addition, it is interesting to study the distribution of iron and thorium in the lunar crust near the HLC. The spatial distribution of Th, which was ejected from the lower levels of proto-Earth, is shown on Figure 16(c). The maximum of Th concentration is located inside of the HLC and displaced on $450 \mathrm{~km}$ from its center in the direction of comet blow. The radius of Th stain is equal to $\sim 780 \mathrm{~km}$. The Fe distribution shifted to $300 \mathrm{~km}$ from the HLC center in the same direction. The Fe strain size has radius of $\sim 700-750 \mathrm{~km}$. Displacement of the both stains, most likely is defined by delay of nuclear excitation of proto-Earth core.

\subsection{The Isotope Analysis ${ }^{39} \mathrm{~K} /{ }^{41} \mathrm{~K}$ of the Visible Side of the Moon}

As well known, the elements such as $\mathrm{Pb}, \mathrm{U}, \mathrm{Th}, \mathrm{Rb}, \mathrm{Sr}, \mathrm{K}, \mathrm{Cr}$, and $\mathrm{Ni}$ have been determined in the series of Apollo missions in rocks and soils samples. Some elements, such as $\mathrm{U}, \mathrm{Rb}, \mathrm{Cr}$, and $\mathrm{Ni}$, show isotopic abundances identical with those of terrestrial materials 

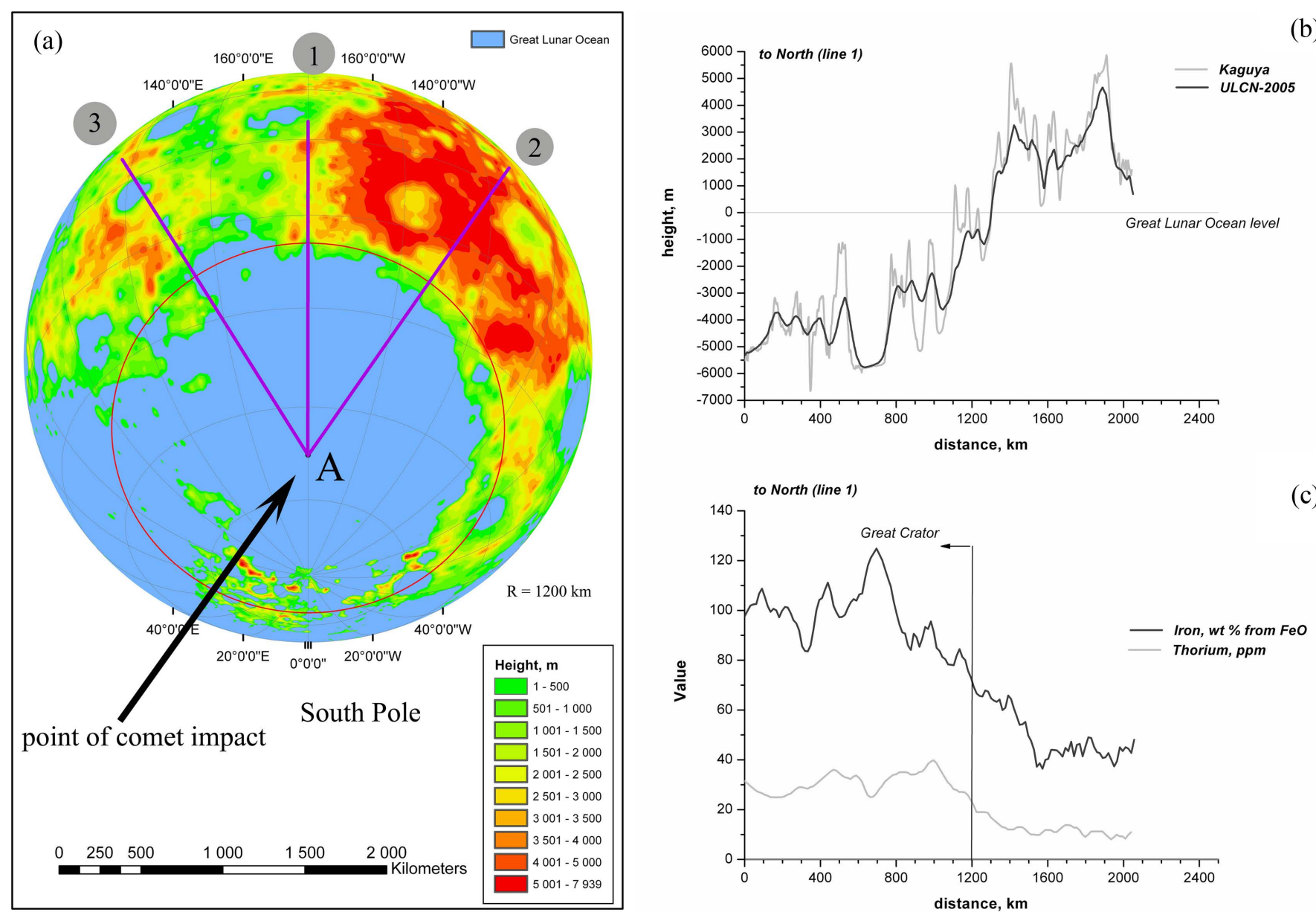

(b)

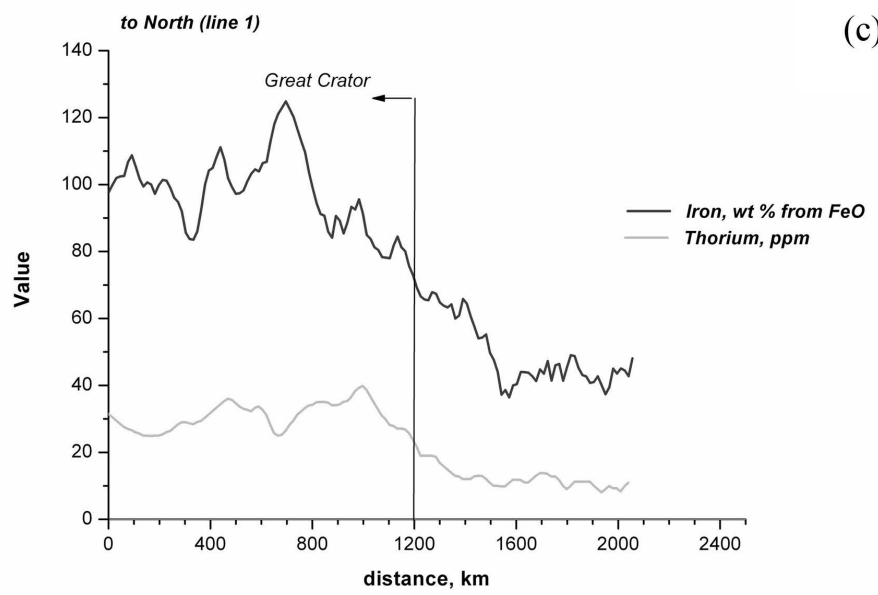

Figure 16. The topography of the opposite side of the Moon zero meters above according to ULCN-2005 is shown (Figure 16(a)). The levels below 0 meters were filled by blue and called as a virtual Great Lunar Ocean. A red contour marked a circle with radius of $1200 \mathrm{~km}$ of the Giant Lunar Crater near the Moon South Pole. The lines 1 - 3 are the directions to the cross-sections. The profiles of the lunar heights according to ULCN-2005 and Kaguya topography along to the line-1 (see Figure 16(a)) from the center of the Giant Lunar Crater are shown in Figure 16(b). The profile of $\mathrm{Fe}$ and Th according to the Lunar Prospector data near the Giant Lunar Crater is presented along the direction of the line-1 in Figure 16(c).

in both types of samples [105]. However, it was shown that there is a definite isotopic fractionation with a relative depletion of up to $0.8 \%-1 \%$ in the ${ }^{39} \mathrm{~K} /{ }^{41} \mathrm{~K}$ ratio in the lunar samples. Also well known the isotopic ratio of ${ }^{39} \mathrm{~K} /{ }^{41} \mathrm{~K}$ such as in lunar samples did not exist in terrestrial materials and meteorites [106].

Let's note that absolute terrestrial ${ }^{39} \mathrm{~K} /{ }^{41} \mathrm{~K}$ ratio is equal $\sim 13.8566 \pm 0.0063$ [107].

The excess of the stable isotope ${ }^{41} \mathrm{~K}$ on the lunar surface is a convincing proof of the thermal nuclear explosion (TNE) of the nuclear upper-level ${ }^{40} \mathrm{~K}$, as at TNE a reaction occurs:

$$
{ }^{40} K+n \rightarrow{ }^{41} K
$$

For those readers, who still doubt the TNE, we will analyze the spatial distribution of ${ }^{39} \mathrm{~K} /{ }^{41} \mathrm{~K}$ ratio on the lunar surface. For this purpose, we use datasets [105] [107] and [108] that were obtained during Apollo 12, 14, 15, 16, 17 missions. Since the results of 

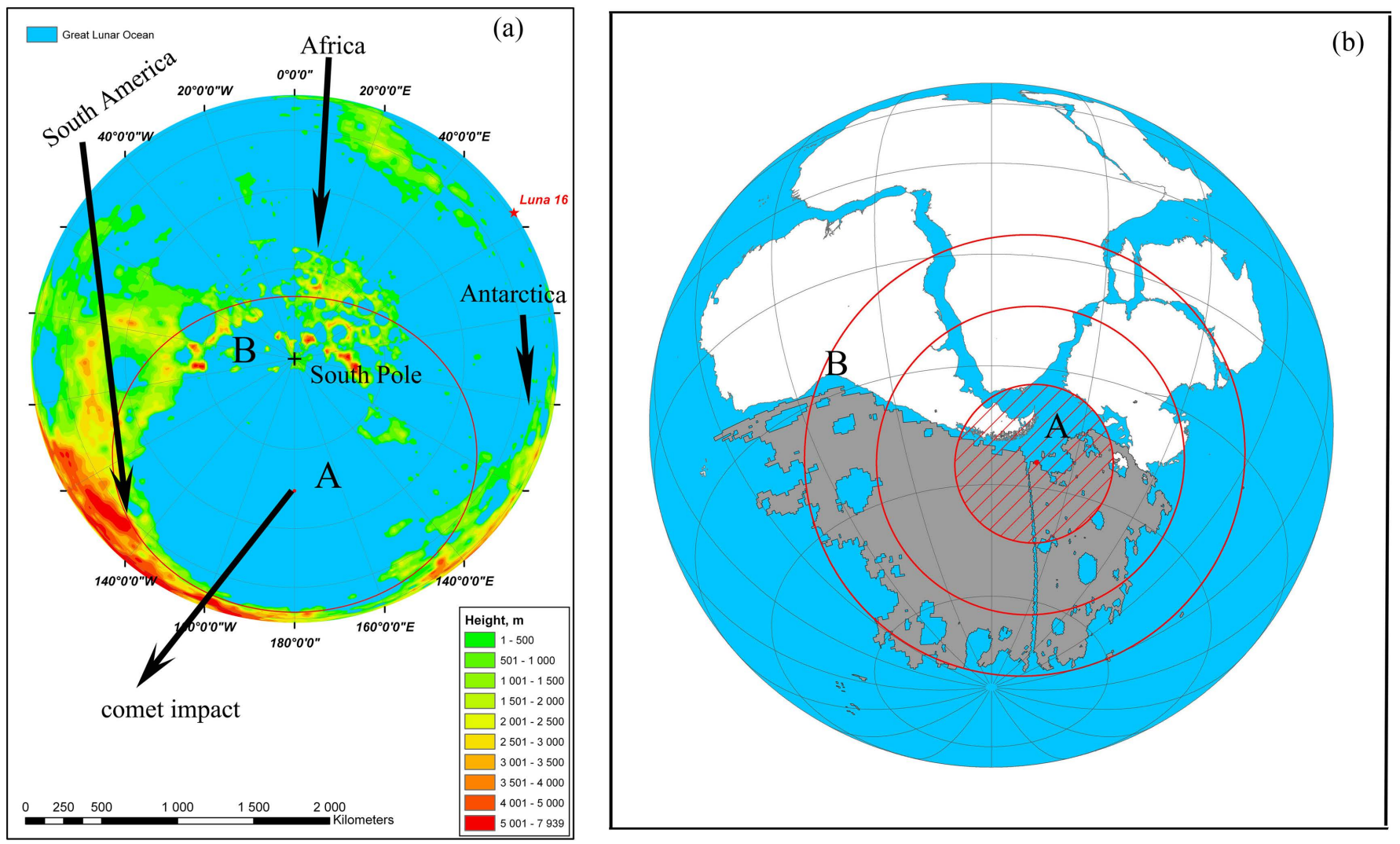

Figure 17. The topography as in Figure 16(a), but in a different projection was shown in Figure 17(a). The locations, in which the lunar continent contacted with South America, Africa and Antarctica, were presented in additional. The A-arrow shows the direction of the comet impact. The conjunction of the lunar continent (see Figure 16(a) and Figure 17(a)) with continents composing Pangea is shown in Figure 17(b).

isotopic analysis are highly dependent on the used sample processing method, the comparison will be carried out separately for each dataset for rock and soil samples.

The ${ }^{39} \mathrm{~K} /{ }^{41} \mathrm{~K}$ ratio gradient was clearly visible for all datasets (see Figure 18 (a) and Figure 18(b)). The closer to the epicenter of a nuclear explosion, the quantity of ${ }^{41} \mathrm{~K}$ isotopes was higher and the ${ }^{39} \mathrm{~K} /{ }^{41} \mathrm{~K}$ ratio was lower, accordingly. Due to the explosion itself occurred within Proto-Earth, and the separation of Earth and Moon occurred in the liquid-drop phase, in Figure 18 the projection of the epicenter on the lunar surface was referred to as the "umbilicus". The positions of Apollo stations as well as the position of the umbilicus are shown in Figure 15(a).

The result of a nuclear explosion has to be present also on the Earth. Let's note that the ${ }^{39} \mathrm{~K} /{ }^{41} \mathrm{~K}$ ratio fractionation does not occur in minerals on a wide scale in the Earth, however the studies [109] [110] and [111] have shown that this ratio has very significant fractionation within heated and stressed xenoliths and in minerals in granite contact zones. It agreed with TNE hypothesis.

\subsection{The Lunar Gravitational Anomalies}

It is of interest to investigate the gravitational anomaly near the Huge Lunar Crater (HLC). 
(a)

- rocks, (Garner et al., 1973)

- soils, (Garner et al., 1973)

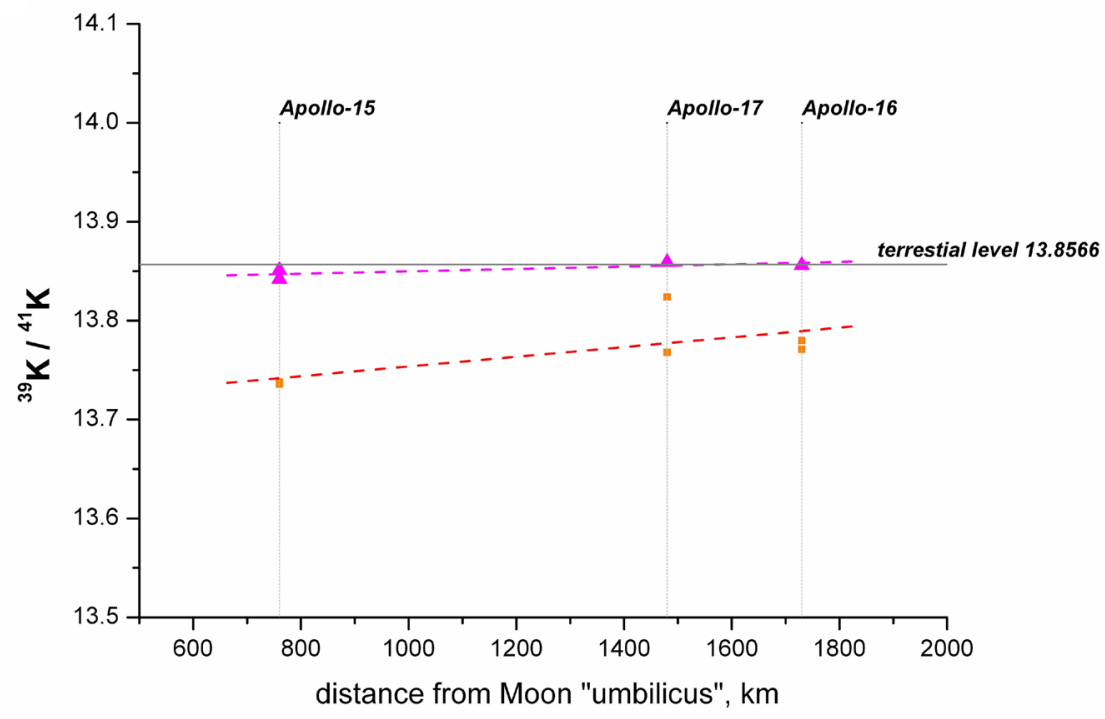

(b)

- rocks, (Garner et al., 1975)

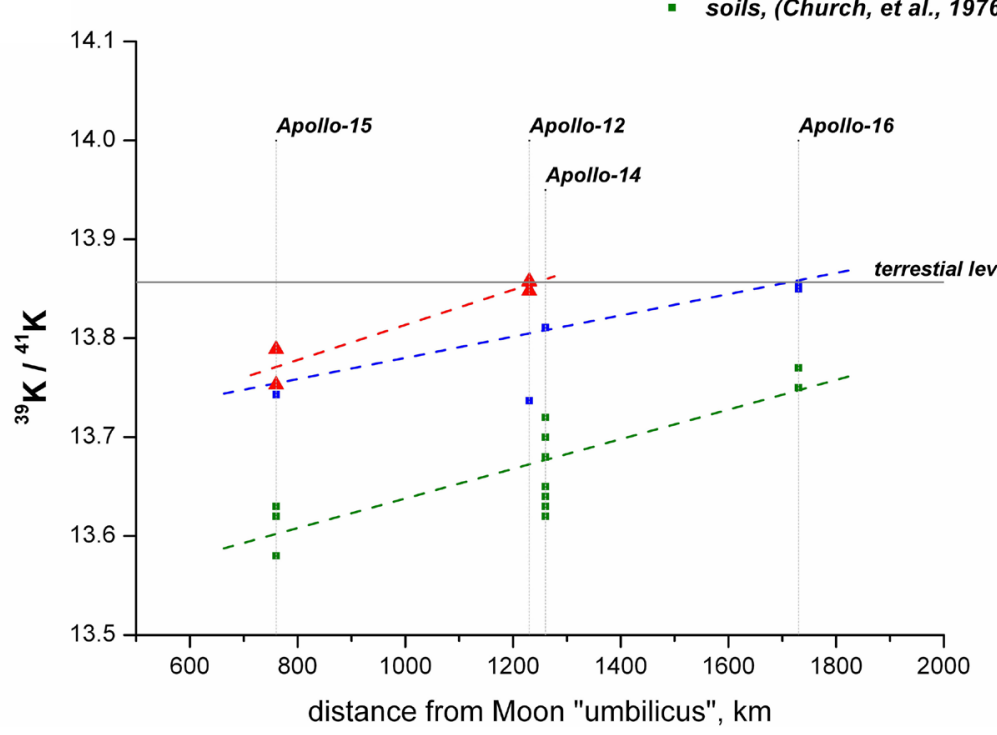

Figure 18. The dependence of ${ }^{39} \mathrm{~K} /{ }^{41} \mathrm{~K}$ ration on distance from a nuclear explosion epicenter ("umbilicus") to Apollo stations was shown for three datasets. The trends for rocks and soils of the lunar samples were presented separately. The constant terrestrial ${ }^{39} \mathrm{~K} /{ }^{41} \mathrm{~K}$ ratio, which is equal to 13.8566 , was shown additionally.

The spatial distribution of gravitational field is presented in Figure 19(a). The sectional view of gravitational field along the lines of $1-3$ is shown in Figure 19(b). The label 3-3 in figures denotes the third maximum on the third line (see Figure 19(a) and Figure 19(b)). The shock waves begin to be recorded at a $1000 \mathrm{~km}$ distance from the center of HLC. The line 3 corresponds to a direction on a traverse of the comet impact. The peaks on the line 3 are most well expressed and they correspond to the superposition of two shock waves, propagated in straight and reverse directions. 


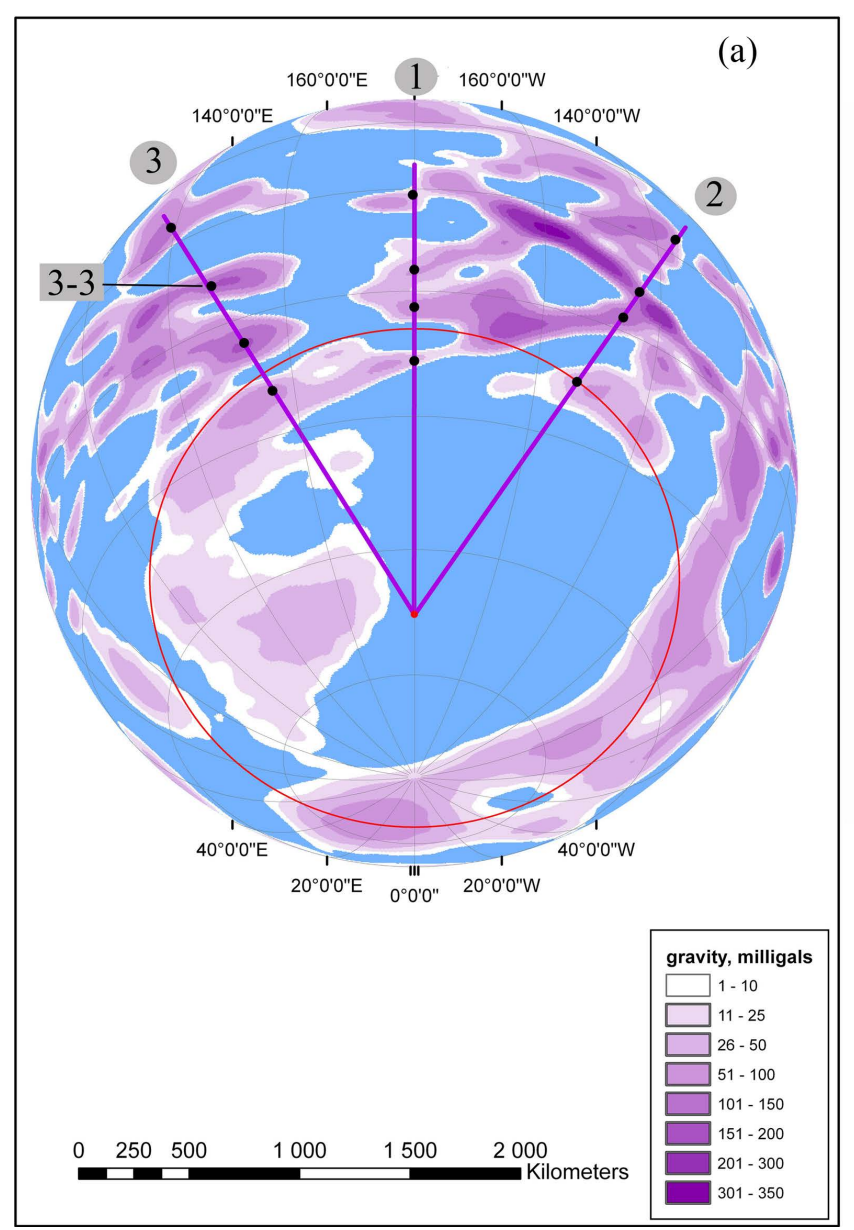

(b)

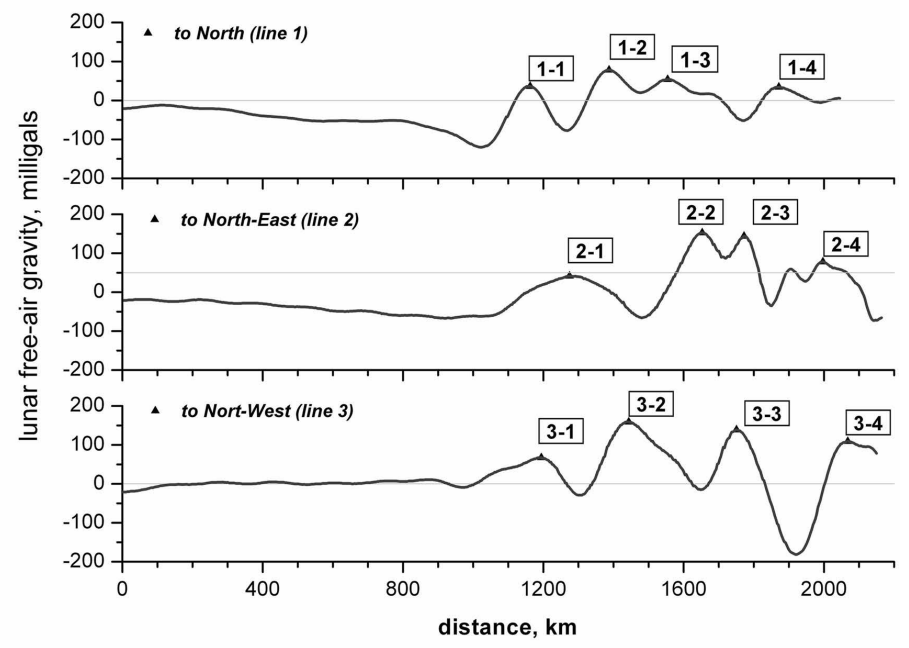

Figure 19. The gravity anomalies as markers of the compression waves, which were obtained from the Clementine/GLGM-2, near the Giant Lunar Crater, are shown in Figure 19(a). The crater is marked as a red ring. The three lines of cross-section directions (line-1, line-2, line-3) are displayed. The points of the gravity maximum were measured from the center of the crater. As an example of their designation one maximum was noted as [3-3] in the rectangle. The profile of free air gravity according to the Clementine/GLGM-2 near the Giant Lunar Crater along the direction of line-1, line-2, line-3 (see Figure 19(a)) is shown in Figure 19(b).

\section{Analysis of Martian and Venus Topography}

\subsection{Martian Topography}

At the next stage of the investigation, it is interesting to study the topography of the Earth's neighboring planets and to find out whether or not these planets were subjected to comets impacts.

In this study, Mars was used as a particular example of a none-tangent comet strike, in which the internal TNE did not lead to the separation of the cap of the Martian nuclear reactor and the products of nuclear explosion basically remained under a planet crust. Let' note, the first Martian nuclear processes investigations were started as early as 1977, when satellite Viking registered in planet atmosphere the extreme values of ${ }^{129} \mathrm{Xe} /{ }^{132} \mathrm{Xe}$ isotopes, which was equal to $2.40 \pm 0.02$ (see [112] [113] [114]).

The topography of Mars is shown in Figure 20(a) and Figure 20(b). For simplicity of perception of bimodality of Mars topography, the levels below zero were filled by 

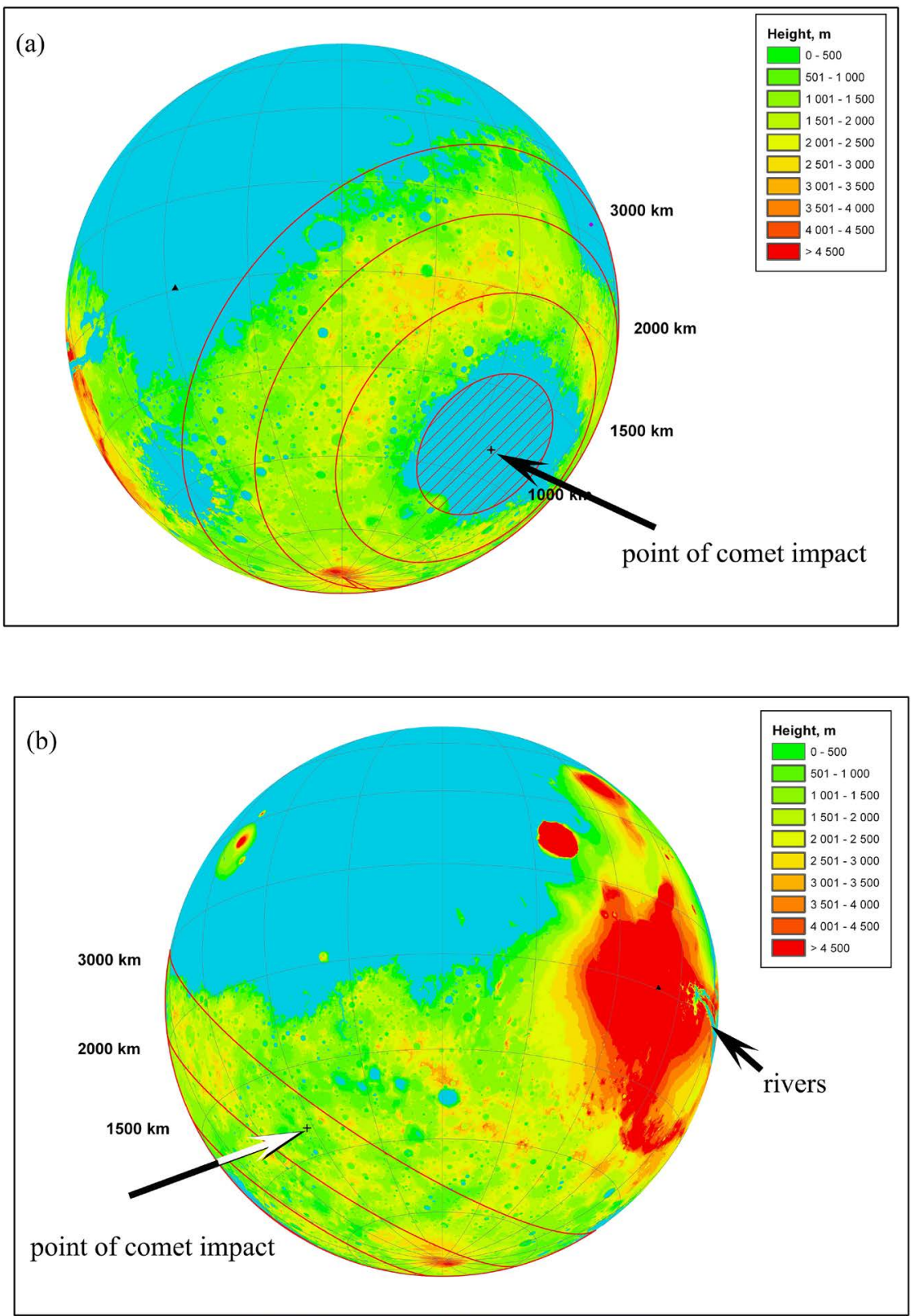

Figure 20. The topography of Mars zero meters above Martian surface for two sides (a) and (b) are presented. The levels below zero meters were filled by virtual Mars Ocean. The direction of the comet impact is shown as an arrow. The Martian canyons and river systems were marked on (b) side an additional.

virtual ocean, the same way as it was made during the study of the Moon topography. A huge crater with a diameter of more than $1000 \mathrm{~km}$ is shown in Figure 20(a). A circle with a radius of $\sim 1500 \mathrm{~km}$ passes along the ridge of the hill, and the next ring corresponds to the contour of the continent. The triangle in Figure 20(a) shows the Thasis area on a hide side of Mars.

The dramatic Tharsis region of Mars is shown on Figure 20(b) as a red color area. The gigantic Valles Marineris Canyon system (stretching from $265^{\circ} \mathrm{E}$ to $310^{\circ} \mathrm{E}$ ), marked 
as river system, presented in Figure 20(b). The major Tharsis volcanoes: Olympus Mons $\left(18^{\circ} \mathrm{N}, 228^{\circ} \mathrm{E}\right)$, Alba Patera $\left(40^{\circ} \mathrm{N}, 250^{\circ} \mathrm{E}\right)$ and Chryse channels are not shown on Figure 20(b).

Thus, after comet impact to Mars one continent was formed, however a rupture of the planet and satellite formation did not occurred because of that blow has happened not under a sliding angle. Due to the absence of a planet rupture, a water, in the quantities that covers the Earth surface, on the Marian surface is absent. However, as a result of interaction between an atomic hydrogen and $\mathrm{CO}_{2}$ of a comet material, water in the large amounts could be in the cavities under the Marian crust and this water might periodically flow on the surface of Mars through the cracks and craters due to gravitational compression. In the satellite imageries, the rivers and lakes that are dried up now are clearly visible. Let's note that the water ice and $\mathrm{CO}_{2}$ snow have been found on Mars (see for example [115]).

In addition, we will note that during a drilling of the Marian surface the Tunable Laser Spectrometer instrument, which based on board of NASA's Curiosity Mars rover, in late 2013 and early 2014 several times nearby Gale crater $\left(4.5^{\circ} \mathrm{S}, 137^{\circ} \mathrm{E}\right)$ registered a short-term bursts of methane 7.2 $\pm 2.1 \mathrm{ppbv}$ at a background signal, which is equal $0.69 \pm$ 0.25 ppbv (For more details, see [116]). Earlier [117] the detection of giant, globe-girdling methane plumes periodically venting from some localized regions on the Martian surface was announced.

As in atmosphere of Mars insignificant quantity of $\mathrm{CH}_{4}$ was registered, it is necessary to suppose that all methane has passed to hydrate of methane $\mathrm{H}_{2} \mathrm{O}-\mathrm{CH}_{4}-\mathrm{H}_{2} \mathrm{O}$. This gives the grounds for speculations about the presence of biologically active forms of life in the depths of Mars. The biological life in form of multi-cellular organisms can be found near geologic breaks and pipes. Let's note that the view of the sedimentary cyanobacteria existence on the Marian surface was noted in [118]. However, the conditions on the surface of Mars are not ideal for survival of microorganisms and they should perish quickly on the surface of Mars.

Let's remind that Mars also as the Earth has a bimodal topography distribution, while Venus has a single-module distribution (see for example [63] [119]). The bimodal distribution of the planet topography is an original marker of its damage by a large space body.

Thus, the bimodal distribution of the planet topography, the presence of planet satellite, TNE products on the planet surface could be the markers that can help to find a life on remote planets by astronomical instruments.

\subsection{Venus Topography Map}

The topography of Venus was investigated. It was shown that despite of a mono-modal distribution of the topography at least two comets hit the Venus. The first comet hit Venus in the polar region and led to a strong heating of mantle and core. The second comet hit the planet at the "right" angle, but the magma at the time of impact was much overheated, and as a result, the crust at the place of impact has simply puffed up. 

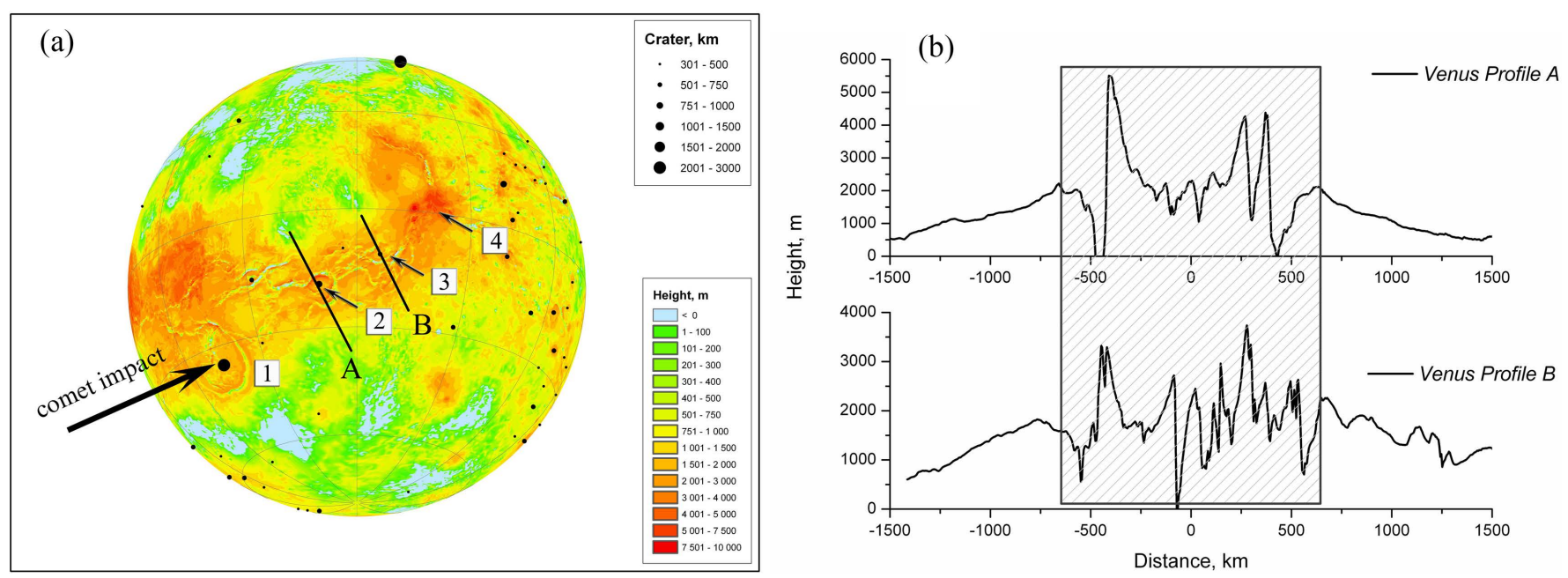

Figure 21. The topography of Venus zero meters above was presented in Figure 20(a). The contours of the continent, below $0 \mathrm{~m}$ were filled by virtual Venus' Ocean. The track of the second comet under the Venus' crust was marked by numbers (1-2-3-4). The longitudinal faults on Venus' surface are clear visible. The craters that are larger than $300 \mathrm{~km}$, are marked as the differentiated points. The Venus' topography of A and B cross sections was shown in Figure 20(b).

This fact is clearly demonstrated in Figure 21(a) in the form of 1-2-3-4 track surface deformation by moving comet under Venusian's crust. The planet's surface near to this track is dotted with numerous cracks (see Figure 21(b)). Currently Venus is overheated, the temperature at the surface is $467^{\circ} \mathrm{C}$ and atmospheric density is equal to $9.2 \mathrm{MPa}$. It will take a long time for the planet to cool down, and to form a crust with thickness of about $30-40 \mathrm{~km}$. Therefore Venus is not suitable for formation of a duplicating inhabited planet in our solar system for a long time.

\section{Results Summarizing}

In this section we will analyze the results obtained earlier and we will show their logical connections.

$r 1$. The study showed that proto-Earth crust before a comet impact was solid and homogeneous. The result of shock waves actions on the crust had revealed poorly expressed anisotropy (Figures 2-4). Solidity of proto-Earth crust allowed increasing the pressure under the planet crust. In case the planet had a soft crust, the comet, which runs through the crust on a tangent, leaved a track on the planet surface. As an example of such case, the comet impact to Venus is discussed in the manuscript (Figure 20(a) and Figure 20(b)).

$r 2$. The result of the overpressure effects and of the shock on the Proto-Earth crust determined the sectoral-bubble shape of the continents. The sectoral form dominated nearby the point of a comet impact; in particular, Southern Africa (Figure 14), India (Figure 8) and southern part of South America have this form (Figure 12). Bubble structure dominated far from the comet impact, namely it presented in the northwestern parts of South America (Figure 12) and Africa (Figure 13), in the eastern part of Australia (Figure 14). Mixed type of sectoral-bubble continent formation represented 


\section{in Antarctica.}

r3. The comet fragments tracing under the Earth's crust were made according to the kimberlite deposits. It is shown that the pressure under the southern part of Africa was above than under the other continents.

$r 4$. Based on the analysis of inclusions in diamond crystals it was found that the gas bubbles in the southern hemisphere near to the point of comet impact basically consisted from $\mathrm{CO}_{2}$, which is the primary comet material. At the same time the diamonds from the northern hemisphere showed that gas bubbles formed in presence of $\mathrm{H}_{2} \mathrm{O}$, $\mathrm{CH}_{4}$ and other impurities such as $\mathrm{K}, \mathrm{Ca}, \mathrm{Mg}$ from the depths up to $600 \mathrm{~km}$. The distribution of the diamond inclusions allows to assert that the comet has not collapsed at approach to proto-Earth.

r5. The topography, chemical species (Th, $\mathrm{Fe}$ ) and gravity anomalies of the Moon were investigated. It is shown that the reverse side of the Moon is raised and formed a geological massif, called as Lunar Continent. The gravitational anomalies reveal the traces of the impact processes near the Giant Lunar Crater (see Figure 18(b)).

16. The reconstruction of Lunar Continent position (Figure 17) was made. It is shown that the Lunar Continent is the missing part of the proto-Earth crust near an impact comet point.

$r 7$. The dating of a comet impact was performed by two ways, which based on the Earth geological scale and on dust deposition on the surface of the Moon. The results of these estimations specify the same time interval.

r8. The modern models suggest that Earth core consists of Fe-Ni with following content in percentage of wt: Fe (85.5), Ni (5.20), Si (6.0) and S (1.90) [120]. Such core structure of a kernel does not provide TNE at impact of a small comet. The new element number model of the Earth inner structure (ENME) was developed. In ENME the boundary between the upper and lower mantle layer corresponds to a layer of fuel ${ }^{40} \mathrm{~K}$. The boundary between the lower mantle and outer core corresponds to ${ }^{137} \mathrm{Cs}$. The core compounds from kernel to become nuclear layers ${ }^{232} \mathrm{Th}^{2}{ }^{235} \mathrm{U}_{-}{ }^{238} \mathrm{U}$. The first nuclear fuel layer is on only $600 \mathrm{~km}$ depth, so an impact with a small comet could lead to TNE.

$r 9$. The suggested geological model provides a simple explanation of the origin of ores in the old geological breaks, and provides a more natural understanding of the continental drift and subduction theory.

$r 10$. It is shown that water on the Earth could be formed in two ways. The first way: the dissociation of $\mathrm{CO}_{2}$ and subsequent reaction with atomic hydrogen, which encountered in TNE. The second way: water could be formed through an acetate way by reacting $\mathrm{CO}_{2}$ with molecular hydrogen $\left(\mathrm{H}_{2}\right)$ at a later stage of the Earth's core cooling after TNE.

$r 11$. The possibility for a life origin from nuclear reaction products after ocean cooling was discussed. As an example of production of amino acids, the reactions for serine and $\alpha$-alanine, that formed shortly thereafter the TNE, were presented.

The $r 1-r 11$ remarks are the result of complex analysis and provide a possibility to make the main conclusion of this study. 


\section{Conclusions}

The principle of the creation of habitable planets near stars in our galaxy was developed.

It was shown that the Earth and Moon were formed as a result of a collision with a small comet. At collision, the comet has broken through the proto-Earth crust, and has created conditions for liquid-drop division into the Earth and the Moon.

After comet impact, which tangent run through the proto-Earth crust $650 \mathrm{Ma}$ ago, the pressure under the proto-Earth crust increased and it has led to delay of thermal nuclear explosion. In this study, it is shown that as a result of gas bubbles formation and the explosion, the Proto-Earth crust lifted up and the continent formation has started. Also the part of the proto-Earth crust nearby the point of comet impact has been thrown out into space. The main mass of the Moon separated from the proto-Earth in the form of a liquid mass with some delay from a break, which was in the central part of water area of the modern Pacific Ocean. The interaction of an atomic reactor ${ }^{1} \mathrm{H}$ with proto-Earth atmosphere and with a comet material has led to the formation of the seas and oceans. As a result, the conditions for life origin occurred.

The disaster at the nuclear plant in Fukushima-I clearly showed how it was easy by failure in the cooling system to break down the unstable thermodynamic balance in nuclear reactors. Therefore, the creation of a second habitable planet in our Solar system is possible by now. There are no doubts that through the certain period of time we will be able to reach remote stars, so the possibility of establishing habited bases on the remote stars is already purely technical issue.

\section{Acknowledgements}

The author gratefully acknowledges colleagues and my wife for suggesting the topic of this paper and for the very thorough revision of the manuscript.

\section{Author Contributions}

A. N. Safronov designed the study, analyzed the data, made model simulations and wrote the manuscript.

\section{Conflicts of Interest}

The authors declare no conflict of interest.

\section{References}

[1] Hartmann, W.K. Ed. (1986) Origin of the Moon. Lunar and Planetary Institute, Houston, Texas.

[2] Benz, W., Slattery, W.L. and Cameron, A.G.W. (1986) The Origin of the Moon and the Single-Impact I. ICARUS, 66, 515-535. https://doi.org/10.1016/0019-1035(86)90088-6

[3] Benz, W., Slattery, W.L. and Cameron, A.G.W. (1987) The Origin of the Moon and the Single-Impact Hypothesis II. ICARUS, 71, 30-45.

https://doi.org/10.1016/0019-1035(87)90160-6 
[4] Benz, W., Cameron, A.G.W. and Melosh, H.J. (1989) The Origin of the Moon and the Single-Impact Hypothesis III. ICARUS, 81, 113-131.

https://doi.org/10.1016/0019-1035(89)90129-2

[5] Cameron, A.G.W. and Benz, W. (1991) The Origin of the Moon and the Single Impact Hypothesis IV. ICARUS, 92, 204-216. https://doi.org/10.1016/0019-1035(91)90046-V

[6] Cameron, A.G.W. (1997) The Origin of the Moon and the Single Impact Hypothesis V. ICARUS, 126, 126-137. https://doi.org/10.1006/icar.1996.5642

[7] Voronin, D.V. (2011) Computer Modeling of Planet Partial Fragmentation. WSEAS Transactions on Fluid Mechanics, 1, 32-50.

[8] de Meijer, R.J., Anisichkin, V.F. and van Westrenen, W. (2013) Forming the Moon from Terrestrial Silicate-Rich Material. Chemical Geology, 345, 40-49. https://doi.org/10.1016/j.chemgeo.2012.12.015

[9] Darwin, G.H. (1879) On the Bodily Tides of Viscous and Semi-Elastic Spheroids, and on the Ocean Tides upon a Yielding Nucleus. Philosophical Transactions of the Royal Society of London, 170, 1-35. https://doi.org/10.1098/rstl.1879.0061

[10] Jeffreys, H. (1930) Amplitude of Tidal Resonances. Monthly Notices of the Royal Astronomical Society, 91, 169-173. https://doi.org/10.1093/mnras/91.1.169

[11] Ringwood, A.E. (1960) Some Aspects of the Thermal Evolution of the Earth. Geochimica et Cosmochimica Acta, 20, 241-249. https://doi.org/10.1016/0016-7037(60)90076-4

[12] Ringwood, A.E. (1986) Composition and Origin of the Moon. In: Hartmann, W.K., Ed., Origin of the Moon, Lunar and Planetary Institute, Houston, Texas, 673-698.

[13] Wise, D.U. (1969) Origin of the Moon from the Earth: Some New Mechanisms and Comparisons. Journal of Geophysical Research: Planets, 74, 6034-6045. https://doi.org/10.1029/JB074i025p06034

[14] Hartmann, W.K. and Davis, D.R. (1975) Satellite-Sized Planetesimals and Lunar Origin. ICARUS, 24, 504-514. https://doi.org/10.1016/0019-1035(75)90070-6

[15] Cameron, A.G.W. and Ward, W.R. (1976) The Origin of the Moon. Lunar and Planetary Science Conference, Houston, Texas, 15-19 March 1976, 120-122.

[16] Clayton, R.N. and Mayeda, T.K. (1996) Oxygen Isotopic Studies of Achondrites. Geochimica et Cosmochimica Acta, 60, 1999-2017. https://doi.org/10.1016/0016-7037(96)00074-9

[17] Wiechert, U., Halliday, A.N., Lee, D.C., Snyder, G.A., Taylor, L.A. and Rumble, D. (2001) Oxygen Isotopes and the Moon-Forming Giant Impact. Science, 294, 345-348. https://doi.org/10.1126/science.1063037

[18] Shukolyukov, A. and Lugmair, G.W. (2000) On the ${ }^{53} \mathrm{Mn}$ Heterogeneity in the Early Solar System. Space Science Reviews, 92, 225-236. https://doi.org/10.1023/A:1005243228503

[19] Trinquier, A., Birck, J.L., Allegre, C.J., Gopel, C. and Ulfbeck, D. (2008) ${ }^{53} \mathrm{Mn}-{ }^{53} \mathrm{Cr}$ Systematics of the Early Solar System Revisited. Geochimica et Cosmochimica Acta, 72, 51465163. https://doi.org/10.1016/j.gca.2008.03.023

[20] Leya, I., Schonbachler, M., Wiechert, U., Krahenbuhl, U. and Halliday, A.N. (2008) Titanium Isotopes and the Radial Heterogeneity of the Solar System. Earth and Planetary Science Letters, 266, 233-244. https://doi.org/10.1016/j.epsl.2007.10.017

[21] Zhang, J., Dauphas, N., Davis, A.M., Leya, I. and Fedkin, A. (2012) The Proto-Earth as a Significant Source of Lunar Material. Nature Geoscience, 5, 251-255. https://doi.org/10.1038/ngeo1429

[22] Humayun, M. and Clayton, R.N. (1995) Potassium Isotope Cosmochemistry: Genetic Implications of Volatile Element Depletion. Geochimica et Cosmochimica Acta, 59, 2131 - 
2148. https://doi.org/10.1016/0016-7037(95)00132-8

[23] Georg, R.B., Halliday, A.N., Schauble, E.A. and Reynolds, B.C. (2007) Silicon in the Earth's Core. Nature, 447, 1102-1106. https://doi.org/10.1038/nature05927

[24] Savage, P.S., Georg, R.B., Armytage, R.M.G., Williams, H.M. and Halliday, A.N. (2010) Silicon Isotope Homogeneity in the Mantle. Earth and Planetary Science Letters, 295, 139-146. https://doi.org/10.1016/j.epsl.2010.03.035

[25] Armytage, R.M.G., Georg, R.B., Savage, P.S., Williams, H.M. and Halliday, A.N. (2011) Silicon Isotopes in Meteorites and Planetary Core Formation. Geochimica et Cosmochimica Acta, 75, 3662-3676. https://doi.org/10.1016/j.gca.2011.03.044

[26] Fitoussi, C. and Bourdon, B. (2012) Silicon Isotope Evidence against an Enstatite Chondrite Earth. Science, 335, 1477-1480. https://doi.org/10.1126/science.1219509

[27] Galimov, E.M. and Krivtsov, A.M. (2005) Origin of the Earth-Moon System. Journal of Earth Systems Science, 114, 593-600. https://doi.org/10.1007/BF02715942

[28] Whiston, W. (1696) A New Theory of the Earth from Its Original to the Consummation of All Things. R. Roberts for Benjamin Tooke, London.

[29] ArcInfo and ArcGlobe. http://www.esri.com/software/arcgis/arcinfo/index.html

[30] Software GPlates v1.5. http://www.gplates.org

[31] Boyden, J.A., Müller, R.D., Gurnis, M., Torsvik, T.H., Clark, J.A., Turner, M., Ivey-Law, H., Watson, R.J. and Cannon, J.S. (2011) Next-Generation Plate-Tectonic Reconstructions Using GPlates. In: Keller, G.R. and Baru, C., Eds., Geoinformatics: Cyber Infrastructure for the Solid Earth Sciences, Cambridge University Press, Cambridge, UK, 95-114. https://doi.org/10.1017/cbo9780511976308.008

[32] Williams, S., Müller, R.D., Landgrebe, T.C.W. and Whittaker, J.M. (2012) An Open-Source Software Environment for Visualizing and Refining Plate Tectonic Reconstructions Using High Resolution Geological and Geophysical Data Sets. GSA Today, 22, 4-9.

[33] Gurnis, M., Turner, M., Zahirovic, S., DiCaprio, L., Spasojevich, S., Müller, R.D., Boyden, J., Seton, M., Manea, V.C. and Bower, D. (2012) Plate Reconstructions with Continuously Closing Plates. Computers and Geosciences, 38, 35-42. https://doi.org/10.1016/j.cageo.2011.04.014

[34] Qin, X., Muller, R.D., Cannon, J., Landgrebe, T.C.W., Heine, C., Watson, R.J. and Turner, M. (2012) Information Model and Markup Language. Geoscientific Instrumentation, Methods and Data Systems, 1, 111-134.

[35] Gilmore, E., Gleditsch, N.P., Lujala, P. and Rød, J.K. (2005) Conflict Diamonds: A New Dataset. Conflict Management and Peace Science, 22, 257-292. https://doi.org/10.1080/07388940500201003

[36] Päivi, L., Gleditsch, N.P. and Gilmore, E. (2005) A Diamond Curse? Civil War and a Lootable Resource. Journal of Conflict Resolution, 49, 538-562. https://doi.org/10.1177/0022002705277548

[37] Gilmore, E., Lujala, P., Gleditsch, N.P. and Rød, J.K. (2015) Datasets Online. Diamond Resources. http://www.prio.no/Data/Geographical-and-Resource-Datasets/Diamond-Resources/

[38] Archinal, B.A., Rosiek, M.R., Kirk, R.L. and Redding, B.L. (2006) Datasets and Description. "The Unified Lunar Control Network 2005". http://pubs.usgs.gov/of/2006/1367/ULCN2005-OpenFile.pdf

[39] Davies, M.E., Colvin, T.R., Meyer, D.L. and Nelson, S. (1994) The Unified Lunar Control Network. JGR, 99, 23211-23214. 
[40] Eliason, E.M., McEwen, A.S., Robinson, M.S., Lee, E.M., Becker, T., Gaddis, L., Weller, L.A., Isbell, C.E., Shinaman, J.R., Duxbury, T. and Malaret, E. (1999) Digital Processing for a Global Multispectral Map of the Moon from the Clementine UVVIS Imaging Instrument. Lunar and Planetary Science $X X X$, Lunar and Planetary Institute, Houston, Abstract No. 1933. http://www.lpi.usra.edu/meetings/LPSC99/pdf/1933.pdf

[41] Eliason, E.M., Lee, E.M., Becker, T.L., Weller, L.A., Isbell, C.E., Staid, M.I., Gaddis, L.R., McEwen, A.S., Robinson, M.S., Duxbury, T., Steutel, D., Blewett, D.T. and Lucey, P.G. Eds. (2003) A Near-Infrared (NIR) Global Multispectral Map of the Moon from Clementine. Lunar and Planetary Institute, Houston. http://www.lpi.usra.edu/meetings/lpsc2003/pdf/2093.pdf

[42] Hare, T.M., Archinal, B.A., Becker, T.L., Lee, E.M., Gaddis, L.R., Redding, B.L. and Rosiek, M.R. (2008) Clementine Mosaics Warped to ULCN 2005 Network. Lunar and Planetary Science XXXIX (2008), Lunar and Planetary Institute, Houston, Abstract No. 2337. http://www.lpi.usra.edu/meetings/lpsc2008/pdf/2337.pdf

[43] Archinal, B.A., Rosiek, M.R., Kirk, R.L. and Redding, B.L. (2006) The Unified Lunar Control Network 2005. http://pubs.usgs.gov/of/2006/1367/ULCN2005-OpenFile.pdf

[44] Dataset: Global GIS Lunar (2010). ftp://pdsimage2.wr.usgs.gov/pub/pigpen/moon/Global_GIS_Lunar/LunarGISDVD_v07.zip

[45] Araki, H., Tazawa, S., Noda, H., Ishihara, Y., Goossens, S., Sasaki, S., Kawano, N., Kamiya, I., Otake, H., Oberst, J. and Shum, C. (2009) Lunar Global Shape and Polar Topography Derived from Kaguya-LALT Laser Altimetry. Science, 323, 897-900. https://doi.org/10.1126/science.1164146

[46] Irion, R. (1998) Lunar Prospector Probes Moon's Core Mysteries. Science, 281, 1423-1425. https://doi.org/10.1126/science.281.5382.1423

[47] Feldman, W.C., Prettyman, T.H., Belian, R.D., Elphic, R.C., Gasnault, O., Lawrence, D.J., Lawson, S.L., Moore, K.R., Binder, A.B. and Maurice, S. Datasets: Lunar Prospector Reduced Spectrometer Data-Special Products. http://pds-geosciences.wustl.edu/missions/lunarp/reduced_special.html

[48] Feldman, W.C., Barraclough, B.L., Fuller, K.R., Lawrence, D.J., Maurice, S., Miller, M.C., Prettyman, T.H. and Binder, A.B. (1999) The Lunar Prospector Gamma-Ray and Neutron Spectrometers. Nuclear Instruments and Methods in Physics Research A, 422, 562-566. https://doi.org/10.1016/S0168-9002(98)00934-6

[49] Lawrence, D.J., Elphic, R.C., Feldman, W.C., Gasnault, O., Genetay, I., Maurice, S. and Prettyman, T.H. (2002) Optimizing the Spatial Resolution for Gamma-Ray Measurements of Thorium Abundances on the Lunar Surface. New Views of the Moon, Europe, 12-14 January 2002.

[50] Lawrence, D.J., Elphic, R.C., Feldman, W.C., Gasnault, O., Genetay, I., Maurice, S. and Prettyman, T.H. (2002) Small-Area Thorium Enhancements on the Lunar Surface. 33rd Lunar and Planetary Science Conference, League City, Texas, 11-15 March 2002, Abstract $\# 1970$.

[51] Elphic, R.C., Lawrence, D.J., Feldman, W.C., Barraclough, B.L., Maurice, S., Binder, A.B. and Lucey, P.G. (2000) Determination of Lunar Global Rare Earth Element Abundances Using Lunar Prospector Neutron Spectrometer Observations. Journal of Geophysical Research, 105, 333-320, 346.

[52] Zuber, M.T., Smith, D.E., Lemoine, F.G. and Neumann, G.A. (1994) The Shape and Internal Structure of the Moon from the Clementine Mission. Science, 266, 1839-1843, https://doi.org/10.1126/science.266.5192.1839 
[53] Smith, D.E., Zuber, M.T., Neumann, G.A. and Lemoine, F.G. (1997) Topography of the Moon from the Clementine Lidar. Journal of Geophysical Research: Planets, 102, 15911611. https://doi.org/10.1029/96JE02940

[54] Lemoine, F.G.R., Smith, D.E., Zuber, M.T., Neumann, G.A. and Rowlands, D.D. (1997) A 70th Degree Lunar Gravity Model (GLGM-2) from Clementine and Other Tracking Data. Journal of Geophysical Research: Planets, 102, 16339-16359.

https://doi.org/10.1029/97JE01418

[55] Datasets: Global GIS Mars. ftp://pdsimage2.wr.usgs.gov/pub/pigpen/mars/Global_GIS_Mars/

[56] Zuber, M.T., Smith, D.E., Phillips, R.J., Solomon, S.C., Banerdt, W.B., Neumann, G.A. and Aharonson, O. (1998) Shape of the Northern Hemisphere of Mars from the Mars Orbiter Laser Altimeter (MOLA). Geophysical Research Letters, 25, 4393-4396. https://doi.org/10.1029/1998GL900129

[57] Smith, D.E., Zuber, M.T., Frey, H.V., Garvin, J.B., Head, J.W., Muhleman, D.O., Pettengill, G.H., Phillips, R.J., Solomon, S.C., Zwally, H.J., Banerdt, W.B. and Duxbury, T.C. (1998) Topography of the Northern Hemisphere of Mars from the Mars Orbiter Laser Altimeter. Science, 279, 1686-1692. https://doi.org/10.1126/science.279.5357.1686

[58] Afzal, R.S. (1994) Mars Observer Laser Altimeter: Laser Transmitter. Applied Optics, 33, 3184-3188. https://doi.org/10.1364/AO.33.003184

[59] Dataset: Venus Global GIS. ftp://pdsimage2.wr.usgs.gov/pub/pigpen/venus/Global_GIS_Venus/

[60] Saunders, R.S. and Pettengill, G.H. (1991) Magellan: Mission Summary. Science, 252, 247249. https://doi.org/10.1126/science.252.5003.247

[61] Saunders, R.S., Spear, A.J., Allin, P.C., Austin, R.S., Berman, A.L., Chandlee, R.C., Clark, J., Decharon, A.V., De Jong, E.M., Griffith, D.G., Gunn, J.M., Johnson, W.T.K., Kirby, C.E., Leung, K.S., Michaels, G.A., Miller, J., Miller, J., Morris, R.B., Morrison, A.D., Piereson, R.G., Scott, J.F., Scott, J.F., Shaffer, S.J., Slonski, J.P., Stofan, E.R., Thompson, T.W., Hensley, S., Lyons, D.T. and Wall, S. (1992) Magellan Mission Summary. Journal of Geophysical Research, 97, 13067-13090. https://doi.org/10.1029/92je01397

[62] Ford, P.G. and Pettengill, G.H. (1992) Venus Topography and Kilometer-Scale Slopes. Journal of Geophysical Research, 97, 13103-13114. https://doi.org/10.1029/92je01085

[63] Ivanova, M.A., Head, J.W. and Basilevskya, A.T. (2015) History of the Long Wavelength Topography of Venus. Solar System Research, 49, 1-11. https://doi.org/10.1134/S0038094615010025

[64] Meyer, F.J. and Sandwell, D.T. (2012) SAR Interferometry at Venus for Topography and Change Detection. Planetary and Space Science, 73, 130-144. https://doi.org/10.1016/j.pss.2012.10.006

[65] Barker, J.L. and Anders, E. (1968) Accretion Rate of Cosmic Matter from Iridium and Osmium Contents of Deepsea Sediments. Geochimica et Cosmochimica Acta, 32, 627-645. https://doi.org/10.1016/0016-7037(68)90053-7

[66] Ceplecha, Z. (1992) Influx of Interplanetary Bodies onto Earth. Astronomy and Astrophysics, 263, 361-366.

[67] Ceplecha, Z. (1996) Luminous Efficiency Based on Photographic Observations of the LostCity Fireball and Implications for the Influx of Interplanetary Bodies onto Earth. Astronomy and Astrophysics, 311, 329-332.

[68] Wegener, A. (1915) The Origin of Continents and Oceans. Dover Publications, New York.

[69] Smith, A.G. and Hallam, A. (1970) The Fit of the Southern Continents. Nature, 225, 139- 
144. https://doi.org/10.1038/225139a0

[70] Smith, A.G. and Briden, J.C. (1977) Mesozoic and Cenozoic Paleocontinental Maps. Cambridge University Press, Cambridge, UK.

[71] Scotese, C.R., Gahagan, L.M. and Larson, R.L. (1988) Plate Tectonic Reconstructions of the Cretaceous and Cenozoic Ocean Basins. Tectonophysics, 155, 27-48. https://doi.org/10.1016/0040-1951(88)90259-4

[72] Scotese, C.R. (1991) Jurassic and Cretaceous Plate Tectonic Reconstructions. Palaeogeography, Palaeoclimatology, Palaeoecology, 87, 493-501. https://doi.org/10.1016/0031-0182(91)90145-H

[73] Golonka, J. and Ford, D. (2000) Pangean (Late Carboniferous-Middle Jurassic) Paleoenvironment and Lithofacies. Palaeogeography, Palaeoclimatology, Palaeoecology, 161, 1-34. https://doi.org/10.1016/S0031-0182(00)00115-2

[74] Golonka, J. (2007) Late Triassic and Early Jurassic Palaeogeography of the World. Palaeogeography, Palaeoclimatology, Palaeoecology, 244, 297-307. https://doi.org/10.1016/j.palaeo.2006.06.041

[75] Schettino, A. and Turco, E. (2009) Breakup of Pangaea and Plate Kinematics of the Central Atlantic and Atlas Regions. Geophysical Journal International, 178, 1078-1097. https://doi.org/10.1111/j.1365-246X.2009.04186.x

[76] Müller, R.D., Sdrolias, M., Gaina, C., Steinberger, B. and Heine, C. (2008) Long-Term Sealevel Fluctuations Driven by Ocean Basin Dynamics. Science, 319, 1357-1362. https://doi.org/10.1126/science.1151540

[77] Hager, B.H. and O’Connell, R.J. (1981) A Simple Global Model of Plate Dynamics and Mantle Convection. Journal of Geophysical Research: Planets, 86, 4843-4867. https://doi.org/10.1029/JB086iB06p04843

[78] Lithgow-Bertelloni, C. and Richards, M. (1998) The Dynamics of Cenozoic and Mesozoic Plate Motions. Reviews of Geophysics, 36, 27-78. https://doi.org/10.1029/97RG02282

[79] Conrad, C. and Lithgow-Bertelloni, C. (2002) How Mantle Slabs Drive Plate Tectoncs. Science, 298, 207-209. https://doi.org/10.1126/science.1074161

[80] Stadler, G., Gurnis, M., Burstedde, C., Wilcox, L., Alisic, L. and Ghattas, O. (2010) The Dynamics of Plate Tectonics and Mantle Flow: From Local to Global Scales. Science, 329, 1033. https://doi.org/10.1126/science.1191223

[81] Seton, M., Müller, R.D., Zahirovic, S., Gaina, C., Torsvik, T., Shephard, G., Talsma, A., Gurnis, M., Turner, M., Maus, S. and Chandler, M. (2012) Global Continental and Ocean Basin Reconstructions Since 200 Ma. Earth-Science Reviews, 113, 212-270. https://doi.org/10.1016/j.earscirev.2012.03.002

[82] Sandwell, D.T., Müller, R.D., Smith, W.H.F., Garcia, E. and Francis, R. (2014) New Global Marine Gravity Model from CryoSat-2 and Jason-1 Reveals Buried Tectonic Structure. Science, 346, 65-67. https://doi.org/10.1126/science.1258213

[83] Earth Byte Group Publications School of Geosciences, University of Sydney, New South Wales, Australia. www.earthbyte.org/publications-archive/

[84] Powell, C.M., McElhinny, M.W., Li, Z.X., Meert, J.G. and Park, J.K. (1993) Paleomagnetic Constraints on Timing of the Neoproterozoic Breakup of Rodinia and the Cambrian Formation of Gondwana. Geology, 21, 889-892. https://doi.org/10.1130/0091-7613(1993)021<0889:PCOTOT>2.3.CO;2

[85] Powell, C.M., Preiss, W.V., Gatehouse, C.G., Krapez, B. and Li, Z.X. (1994) South Australian Record of a Rodinian Epicontinental Basin and Its Mid-Neoproterozoic Breakup ( 700 $\mathrm{Ma})$ to Form the Palaeo-Pacific Ocean. Tectonophysics, 237, 113-140. 
https://doi.org/10.1016/0040-1951(94)90250-X

[86] Dalziel, I.W. (1997) Neoproterozoic-Paleozoic Geography and Tectonics: Review, Hypothesis, Environmental Speculation. Geological Society of America Bulletin, 109, 16-42. https://doi.org/10.1130/0016-7606(1997)109<0016:ONPGAT>2.3.CO;2

[87] Kirschvink, J.L. (1992) Late Proterozoic Low-Latitude Global Glaciation: The Snowball Earth. In: Schopf, J. and Klein, C. Eds., In the Proterozoic Biosphere: A Multidisciplinary Study, Cambridge University Press, Cambridge, UK, 51-52.

[88] Kadyshevich, E.A. and Ostrovskii, V.E. (2009) Hydrate Hypothesis of Living Matter Origination (LOH-hypothesis). Journal of Thermal Analysis and Calorimetry, 95, 571-578. https://doi.org/10.1007/s10973-008-9546-5

[89] Morgan, J.W. and Anders, E. (1980) Chemical Composition of Earth, Venus, and Mercury. Proceedings of the National Academy of Sciences of the United States of America, 77, 69736977. https://doi.org/10.1073/pnas.77.12.6973

[90] Brown, G.C. and Mussett, A.E. (1981) The Inaccessible Earth. An Integrated View to Its Structure and Composition. Allen \& Unwin, London.

[91] Turcotte, D.L. and Schubert, G. (2002) Geodynamics. Cambridge University Press, Cambridge, England, UK.

[92] Lowrie, W. (2007) Fundamentals of Geophysics. Cambridge University Press, Cambridge, UK. https://doi.org/10.1017/CBO9780511807107

[93] Dawson, J.B. (1980) Kimberlites and Their Xenoliths. Springer, Berlin. https://doi.org/10.1007/978-3-642-67742-7

[94] Brenker, F.E., Vollmer, C., Vincze, L., Vekemans, B., Szymanski, A., Janssens, K., Szaloki, I., Nasdala, L. and Kaminsky, F. (2007) Carbonates from the Lower Part of Transition Zone or Even the Lower Mantle. Earth and Planetary Science Letters, 260, 1-9. https://doi.org/10.1016/j.epsl.2007.02.038

[95] Wirth, R., Kaminsky, F., Matsyuk, S. and Schreiber, A. (2009) Unusual Micro- and Nano-Inclusions in Diamonds from the Juina Area, Brazil. Earth and Planetary Science Letters, 286, 292-303. https://doi.org/10.1016/j.epsl.2009.06.043

[96] Kaminsky, F.V., Khachatryan, G.K., Andreazza, P., Araujo, D. and Griffin, W.L. (2009) Super-Deep Diamonds from Kimberlites in the Juina Area, Mato Grosso State, Brazil. Lithos, 112S, 833-842. https://doi.org/10.1016/j.lithos.2009.03.036

[97] Sobolev, N.V., Kaminsky, F.V., Griffin, W.L., Efimova, E.S., Win, T.T., Ryan, C.G. and Botkunov, A. (1997) Mineral Inclusions in Diamonds from the Sputnik Kimberlite Pipe, Yakutia. Lithos, 39, 135-157. https://doi.org/10.1016/S0024-4937(96)00022-9

[98] Wirth, R., Vollmer, C., Brenker, F., Matsyuk, S. and Kaminsky, F. (2007) Nanocrystalline Hydrous Aluminium Silicate in Superdeep Diamonds from Juina (Mato Grosso State, Brazil). Earth and Planetary Science Letters, 259, 384-399. https://doi.org/10.1016/j.epsl.2007.04.041

[99] Walter, M.J., Bulanova, G.P., Armsrong, L.S., Keshav, S., Blundy, J.D., Gudfinnsson, G., Lrd, O.T., Lennie, A.R., Cark, S.M., Smth, C.B. and Gobbo, L. (2008) Primary Carbonatite melt from Deeply Subducted Oceanic Crust. Nature, 454, 622-625. https://doi.org/10.1038/nature07132

[100] Hayman, P.C., Kopylova, M.G. and Kaminsky, F.V. (2005) Lower Mantle Diamonds from Rio Soriso (Juina, Brazil). Contributions to Mineralogy and Petrology, 149, 430-445. https://doi.org/10.1007/s00410-005-0657-8

[101] Kaminsky, F., Wirth, R., Matsyuk, S., Schreiber, A. and Thomas, R. (2009) Nyerereite and Nahcolite Inclusions in Diamond: Evidence for Lower-Mantle Carbonatitic Magmas. $\mathrm{Mi}$ - 
neralogical Magazine, 73, 797-816. https://doi.org/10.1180/minmag.2009.073.5.797

[102] Bulanova, G.P., Walter, M.J., Smith, C.B., Kohn, S.C., Armstrong, L.S., Blundy, J. and Gobbo, L. (2010) Mineral Inclusions in Sublithospheric Diamonds from Collier 4 Kimberlite Pipe, Juina, Brazil: Subducted Protoliths, Carbonated Melts and Primary. Geophysical Research Abstracts, 12, EGU2010-5268-2012. https://doi.org/10.1007/s00410-010-0490-6

[103] Stachel, T., Harris, J.W., Brey, G.P. and Joswig, W. (2000) Kankan Diamonds (Guinea) II: Lower Mantle Inclusion Parageneses. Contributions to Mineralogy and Petrology, 140, 1627. https://doi.org/10.1007/s004100000174

[104] Kaminsky, F. (2012) Mineralogy of the Lower Mantle: A Review of "Super-Deep" Mineral Inclusions in Diamond. Earth-Science Reviews, 110, 127-147. https://doi.org/10.1016/j.earscirev.2011.10.005

[105] Barnes, I.L., Garner, E.L., Gramlich, J.W., Machlan, L.A., Moody, J.R., Moore, L.J., Murphy, T.J. and Shields, W.R. (1973) Isotopic Abundance Ratios and Concentrations of Selected Elements in Some Apollo 15 and Apollo 16 Samples. Proceedings of the Fourth Lunar Science Conference (Lunar and Planetary Science Institute), Vol. 2, 1197-1207.

[106] Burnett, D.S., Lippolt, H.J. and Wasserburg, G.J. (1966) The Relative Isotopic Abundance of $40 \mathrm{~K}$ in Terrestrial and Meteoritic Samples. Journal of Geophysical Research, 71, 1249-1265. https://doi.org/10.1029/JZ071i004p01249

[107] Garner, E.L., Machlan, L.A. and Barnes, I.L. (1975) The Isotopic Composition of Lithium, Potassium, and Rubidium in Some Apollo 11, 12, 14, 15, and 16 Samples. Proceedings of the Sixth Lunar Science Conference, Houston, Texas, 17-21 March 1975, 1845-1855.

[108] Church, S.E., Tilton, G.R., Wright, J.E. and Lee-Hu, C.-N. (1976) Volatile Element Depletion and ${ }^{39} \mathrm{~K} /{ }^{41} \mathrm{~K}$ Fractionation in Lunar Soils. Proceedings of the Seventh Lunar Science Conference, Houston, Texas, 15-19 March 1976, 423-439.

[109] Schreiner, G.D.L. and Verbeek, A.A. (1965) Variations in ${ }^{39} \mathrm{~K} /{ }^{41} \mathrm{~K}$ Ratio and Movement of Potassium in a Granite-Shale Contact Region. Proceedings of the Royal Society of London. Series A, Mathematical and Physical Sciences, 285, 423-429. https://doi.org/10.1098/rspa.1965.0114

[110] Verbeek, A.A. and Schreiner, G.D.L. (1967) Variations in ${ }^{39} \mathrm{~K} /{ }^{41} \mathrm{~K}$ Ratio and Movement of Potassium in a Granite-Amphibolite Contact Region. Geochimica et Cosmochimica Acta, 31, 2125-2133. https://doi.org/10.1016/0016-7037(67)90056-7

[111] Schreiner, G.D.L. and Welke, H.-J.H.F.D. (1971) Variations in ${ }^{39} \mathrm{~K} /{ }^{41} \mathrm{~K}$ Ratio and Movement of Potassium in Heated and Stressed Zenoliths. Geochimica et Cosmochimica Acta, 35, 719-726. https://doi.org/10.1016/0016-7037(71)90069-X

[112] Owen, T., Biemann, K., Rushneck, D.R., Biller, J.E., Howarth, D.W. and Lafleur, A.L. (1977) The Composition of the Atmosphere at the Surface of Mars. Journal of Geophysical Research: Planets, 82, 4635-4639. https://doi.org/10.1029/JS082i028p04635

[113] Swindle, T.D., Caffee, M.W. and Hohenberg, C.M. (1986) Xenon and Other Noble Gases in Shergottites. Geochimica et Cosmochimica Acta, 50, 1001-1015. https://doi.org/10.1016/0016-7037(86)90381-9

[114] Ocker, K.D. and Gilmour, J.D. (2004) Martian Xenon Components in Shergotty Mineral Separates: Locations, Sources, and Trapping Mechanisms. Meteoritics \& Planetary Science, 39, 1967-1981. https://doi.org/10.1111/j.1945-5100.2004.tb00090.x

[115] Mitrofanov, I., Zuber, M.T., Litvak, M.L., Boynton, W.V., Smith, D.E., Drake, D., Hamara, D., Kozyrev, A.S., Sanin, A.B., Shinohara, C., Saunders, R.S. and Tretyakov, V. (2003) $\mathrm{CO}_{2}$ Snow Depth and Subsurface Water Ice Abundance in the North Hemisphere of Mars. Science, 300, 2081-2084. https://doi.org/10.1126/science.1084350 
[116] Webster, C.R., Mahaffy, P.R., Atreya, S.K., Flesch, G.J., Mischna, M.A., Meslin, P.-Y., Farley, K.A., Conrad, P.G., Christensen, L.E., Pavlov, A.A., Martín-Torres, J., Zorzano, M.-P., McConnochie, T.H., Owen, T., Eigenbrode, J.L., Glavin, D.P., Steele, A., Malespin, C.A., Archer Jr., P.D., Sutter, B., Coll, P., Freissinet, C., McKay, C.P., Moores, J.E., Schwenzer, S.P., Bridges, J.C., Navarro-Gonzalez, R., Gellert, R. and Lemmon, M.T. (2015) Mars Methane Detection and Variability at Gale Crater. Science, 347, 415.

https://doi.org/10.1126/science.1261713

[117] Mumma, M.J., Villanueva, G.L., Novak, R.E., Hewagama, T., Bonev, B.P., DiSanti, M.A., Mandell, A.M. and Smith, M.D. (2009) Strong Release of Methane on Mars in Northern Summer 2003. Science, 323, 1041-1045. https://doi.org/10.1126/science.1165243

[118] Noffke, N. (2015) Ancient Sedimentary Structures in the <3.7 Ga Gillespie Lake Member, Mars, That Resemble Macroscopic Morphology, Spatial Associations, and Temporal Succession in Terrestrial Microbialites. Astrobiology, 15, 169-192.

https://doi.org/10.1089/ast.2014.1218

[119] Aharonson, O., Zuber, M.T. and Rothman, D.H. (2001) Mars Topography Statistics of Mars' Topography from the Mars Orbiter Laser Altimeter' Slopes, Correlations, and Physical Models. Journal of Geophysical Research, 106, 23723-723735. https://doi.org/10.1029/2000JE001403

[120] McDonough, W.F. (2003) Compositional Model for the Earth's Core. Treatise on Geochemistry, 2, 547-568. https://doi.org/10.1016/B0-08-043751-6/02015-6

Submit or recommend next manuscript to SCIRP and we will provide best service for you:

Accepting pre-submission inquiries through Email, Facebook, LinkedIn, Twitter, etc.

A wide selection of journals (inclusive of 9 subjects, more than 200 journals)

Providing 24-hour high-quality service

User-friendly online submission system

Fair and swift peer-review system

Efficient typesetting and proofreading procedure

Display of the result of downloads and visits, as well as the number of cited articles

Maximum dissemination of your research work

Submit your manuscript at: http://papersubmission.scirp.org/

Orcontact ijaa@scirp.org 